Portland State University

PDXScholar

1986

\title{
An historical overview of creativity with implications for education
}

Antoinette S. Ellis

Portland State University

Follow this and additional works at: https://pdxscholar.library.pdx.edu/open_access_etds

Part of the Education Commons, and the Intellectual History Commons Let us know how access to this document benefits you.

\section{Recommended Citation}

Ellis, Antoinette S., "An historical overview of creativity with implications for education" (1986).

Dissertations and Theses. Paper 3592.

https://doi.org/10.15760/etd.5476

This Thesis is brought to you for free and open access. It has been accepted for inclusion in Dissertations and Theses by an authorized administrator of PDXScholar. Please contact us if we can make this document more accessible: pdxscholar@pdx.edu. 
AN ABSTRACT OF THE THESIS OF Antoinette S. Ellis for the Master of Arts in Education presented May 14, 1986

Title: An Historical Dverview of Creativity with Implications for Education

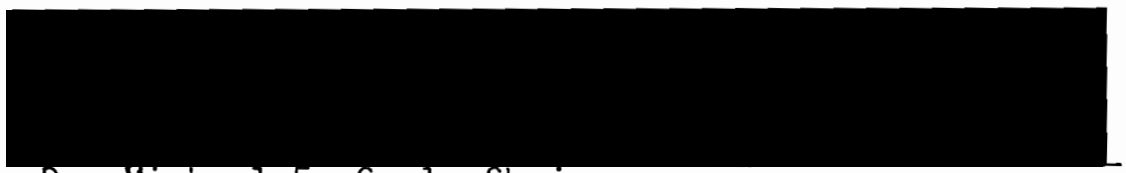

Or. Michael E. Carl, Chairperson
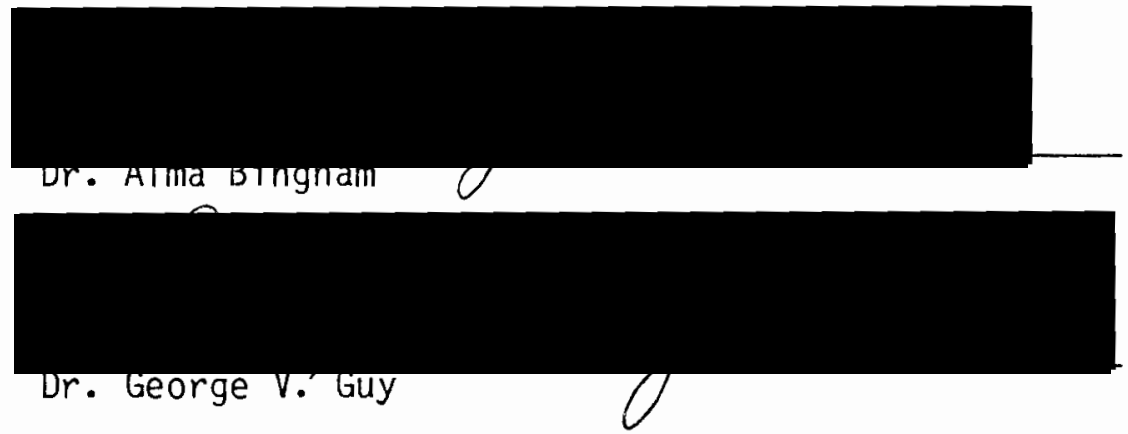

This thesis traced the development of the concept of creativity from the earliest works in the intellectual history of Western civilization to the late twentieth century. This historical perspective on the concept of creativity served as a backdrop to current views of the concept and as a reference source for recurrent views of the concept and as a reference source for recurrent and essential themes in the progressing debates concerning this issue.

The study proceeded from the evidence of Homeric and early philosophical work concerning the lively and real presence in the thinking of the times of experiences of "breakthrough" creative thought and production. The source of inspiration as external to the 
creative person and the conflict between the rational and the irrational in creative works were documented in the early Greek period of the literature as of central importance to the question of creativity. The unfolding of increasingly incisive visions of the source of creativity and of issues related to the production of creative works were then traced through three more recent historic periods: the Italian Renaissance, the eighteenth century European Enlightenment, and finally the modern period 1900-1985. Two dimensions of changes in thought were of particular importance. The first involved the focal point of the source of inspiration. With Renaissance Neoplatonism, the source of inspiration was retrieved from externality and located within the creative person as pure potentiality to be actualized in living. This concept of the internality of creativity was increasingly refined through eighteenth century Cartesian rationalism in France and Neoplatonism in England.

The modern orientation to inspiration has proceeded in the direction of deeper penetration into the personal experience of and the creative process involved in creativity. The question of rationality vs irrationality, which loomed so large in ancient Greece, retreated to a secondary position in the thinking of the Renaissance Neoplatonists and of eighteenth century critical writings. With the pronouncements of Kant at the end of the eighteenth century, rationality vs irrationality descended out of view as a free-standing question or concern for modern times. 
The modern issues that have swelled across the stage concerning creativity have been those of the creative personality, the question of genius, the testing and measurement of creativity and the creative process itself. With the intensive focus of modern sights on issues of personality, a considerable catalogue of multiple personality traits unique to creative persons has emerged leaving education much to absorb and ponder. Testing and measurement of creativity has, perhaps, succeeded in guiding some attention to capacities of creativity among students and adults, but it has, to date, failed to provide reliable and valid instruments for measuring creativity or creative potential. Intellectual or academic giftedness has fared much better in the testing atmosphere of modern times than has creativity which currently may really be measurable only by a combination of intelligence, creativity, and personality tests. Of particular importance are recent suggestions concerning the creative process, most significantly the central process stages of incubation and illumination. It may be in these areas that the precise and distinct qualities of creativity may be isolated.

The conclusions deriving from this overview of creativity involve three central ideas. (1) There has been and continues to be a confusion between intellectual capacities and creative capacities, with the latter most often being subsumed under the former. There is a need for an ultimate and clear discrimination between the two. (2) Once focalized, creativity needs, if possible, to be measured and assessed. Until a reliable creativity metric has been achieved, however, where necessary, a combination of intelligence, creativity, and personality 
tests should be used to identify creative students in schools, albeit tentatively. (3) As all people have creative capacities to one degree or another, it seems that a major objective of education needs to be the encouragement of the growth and development of creativity throughout the entire academic careers of all students. 


\title{
AN HISTORICAL OVERVIEW OF CREATIVITY WITH IMPLICATIONS FOR EDUCATION
}

\author{
by
}

Antoinette S. Ellis

A thesis submitted in partial fulfillment of the requirements for the degree of

\author{
MASTER OF ARTS \\ in \\ EDUCATION
}

Portland State University 
TO THE OFFICE OF GRADUATE STUDIES AND RESEARCH:

The rnembers of the Committee approve the thesis of Antoinette S. Ellis presented May 14, 1986.

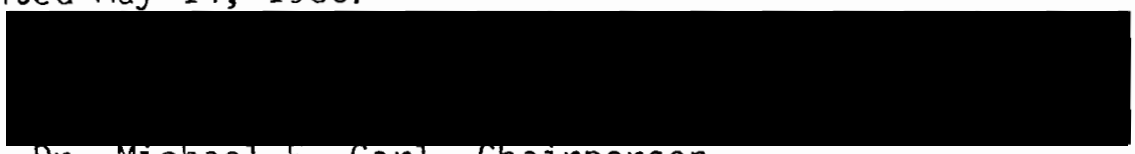

Dr. Michael E. Carl, Chairperson
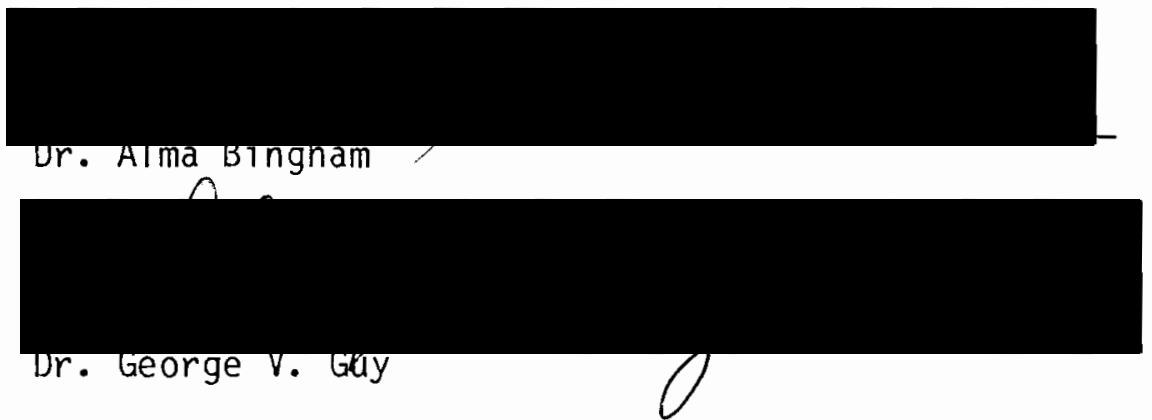

APPROVED:

Robert B. Evernart, vean, School of Education

Bernard Ross, Acting vean of Graduate Studies and Research 


\section{ACKNOW LEDGEMENTS}

All gratitude to my mother and my friend, Paulette A. Ellis, without whose encouraging support this work would not have been possible. Thanks also to Dr. Michael Carl and Dr. Alma Bingham for facilitating passage through the "narrows" encountered in this task. Finally, to Dr. George Guy, 2800 years of gratitude for his help in refining the concepts underlying this thesis and in delivering them to the written page. 
TABLE OF CONTENTS

PAGE

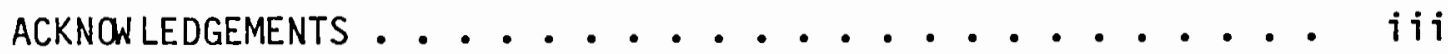

LIST OF FIGURES .................. . . v CHAPTER

I. INTRODUCTION ......................... 1

II. CREATIVITY--THE DEVELOPMENT AND EMERGENCE OF THE

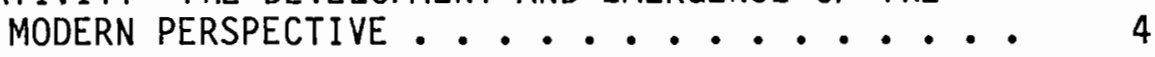

The Ancients .......... . . 4 4

The Italian Renaissance ....... 10

The Eighteenth Century Enlightenment . . . 13

The Birth of the Modern Era: 1900-1950 . . 24

III. CREATIVITY AND EDUCATION . . . . . . . . 37

The Creative Personality . . . . . 38

The Assessment of Creativity . . . . . 44

The Creative Process . . . . . . 53

Additional Essentials in the Process of Creativity........... 62

Inspiration Through Modern Eyes ..... 67

Genius in the Age of Testing . . . . . 72

IV. SUMMARY, CONCLUSIONS AND IMPLICATIONS . . . . 76

Summary .............. 76

Conclusions and Implications...... 87

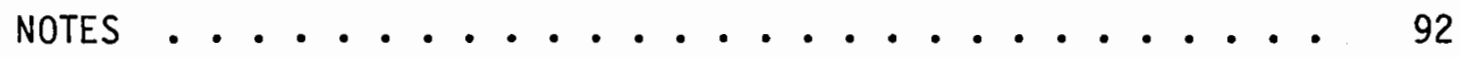

BIBLIOGRAPHY ..................... 109 


\section{LIST OF FIGJRES}

FIGURE

PAGE

1 Stages in Wallas/Patrick's creative process model and Guyilford's problem solving model . . . . 56

2 Stages in Wallas/Patrick's creative process model, Guilford's problem-solving model and Torrance's theory of the process of creating ...... 60 


\section{CHAPTER I}

\section{INTRODUCTION}

Since 1950, psychologists and educators alike have focused unprecedented attention on the issue of creativity in both the professional and the educational spheres of society. While the original interest in creativity in modern times resulted from concerns immediately within the domains of psychology and education, the launching of Sputnik in 1957 galvanized the American nation to the need for greater creativity in the country as a whole, particularly in the sciences and technology. As a result, schools increased emphasis on scientific and mathematics achievement and placed new emphasis on the nurturing and development of innovative and creative talents of students. In the wake of the cybernetics and computer revolutions in the last two decades, the educational emphasis has shifted toward technology, in which innovative applications of learning are part of the instructional expectation.

Although in the 1980 s education has been vigorously redirected toward "excellence" and achievement as assessed by grades and standardized tests, the importance of innovative thinking and creative problem-solving have remained tacit concerns of teachers and the schools. Moreover, business and industry are demanding creative 
and intellectual breakthroughs to further and continue the unprecedented developments in science and technology in the twentieth century. It seems clear that to serve national and global interests, increased achievement within currently known fields and established parameters is not alone what is going to be required for human progress and world peace. The need for technical and intellectual breakthroughs across the full spectrum of human endeavors has never been greater.

If we must call more upon and therefore foster and encourage the creative power of individuals, it would appear that we need a more complete understanding of creativity and the factors involved in its manifestation. A cursory examination of recent writings concerning creativity revealed a confusion about the scope and meaning of the term suggesting that further examination of the concept was required. Based on previous academic studies in philosophy and the arts, the author hypothesized that creativity was enough of a unique human characteristic that some insight may well be gained from an in-depth examination of its treatinent in the literature of the past. Accordingly, a study and review was undertaken of writers and thinkers of antiquity, including Homer and Plato from Hellenic Greece, in order to discern their views regarding this distinctively human trait. Following this review, the author attempted to trace the development of the idea of creativity through two of the most creative eras in western civilization, the Italian Renaissance and the eighteenth century European Enlightenment. Finally, the development of the concept through the late nineteenth century and the twentieth century to the 
present was reviewed with special focus on the emerging conceptualization of creativity since 1950 . While the sources for the review of literature from antiquity to 1950 were generally the acknowledged scholars in the fields of philosophy, aesthetic criticism, and psychology, an ERIC search was conducted to identify significant contributions to the literature since 1950. In an effort to achieve maximum completeness, this search traced references by 19 "descriptors" and a "free text search" across three academic levels. Twentysix Boolean "operators" were used to initiate multiple "overlapping term" searches. The search identified 81 journal articles and 87 ERIC documents related to this subject. From an overview of these materials, key works were identified and reviewed.

In this present work, the author was able to abstract representative concepts of creativity and implicit features of the creative process as conceptualized throughout the Western history of civilization. These visions of man's creativity are presented in Chapters II and III. This study concludes with an over-all summary, followed by conclusions and a discussion of their implications in Chapter IV. 
CHAPTER I I

\section{CREATIVITY --THE DEVELOPMENT AND EMERGENCE OF THE MODERN PERSPECTIVE}

\section{The Ancients}

For Western civilization, the essentially human capacity of creativity came under its first systematic and problematical exploration in the works of Plato $(427-347 \mathrm{BC})$. The most famous and enduring image of great creative talent issuing to us through the centuries from the classic Platonic Dialogues is that of the artist who is, at once, "inspired" and "out of his mind," graced with supernatural powers and touched with madness. In the early dialogue, "Ion," Plato gives his immortal romantic image of the artist or poet in the words: "...the poet is a light and winged and holy thing," 1 followed immediately by a gentle expression of his equally famous hesitation of reason:

... and there is no invention in him until he has been inspired and is out of his senses, and the mind is no longer in him: when he has not attained to this state he is powerless and is unable to utter his oracles (emphasis added). 2

For this double-image of creative greatness, Plato did not assume credit of authorship for either himself or his teacher and main protagonist, Socrates. Even at the end of his momumental philosophi- 
cal work in which, along with other issues, this duple character of creativity is carefully and severely examined, Plato assures his reader that this double-view of the poet (or creative genius) is: "...according to the tradition that has ever prevailed among us, and is accepted of a 11 men...."3

In fact, however, the only part of the image that appears from a modern perspective to have a significant ancient heritage is that of the grace of vision through divine inspiration itself, not the implication of senselessness or madness.

Plato's most immediate source from recognized antiquity was Homer (c. $800 \mathrm{BC}$ ) whose revered Iliad opens with the poet's appeal to divinity for direct inspiration--in fact, for something like immediate divine dictation of the epic:

Sing, goddess, the anger of Peleus' son, Achilleus and its devastation, which put pains thousandfold upon the Achaians.... 4

Although this prologue was, in Homer's time, already a formal style of opening a grand epic, it was by no means empty form. Throughout the heroic tale, Homer charges divinities with his needs for inspiration, information and insight. A dramatic example is encountered at the midpoint in the epic account when the tensions of military preparations have reached the breaking point and the Trojans

whirled about and stood their ground against the Achaians, and the Argives against them pulled together their battle lines. So the fighting grew close and they faced each other, and foremost Agamemnon drove on, trying to fight far ahead of the others. 5

Here Homer breaks the narrative with an appeal to higher powers for vision: 
Tel1 me now, you Muses who have your home on 01 ympus, who was the first to come forth and stand against Agamemnon of the very Trojans, or their renowned companions in battle. 6

It is apparent through the Homeric tradition that divine inspiration was not reserved by the poet for his work alone as the privileged fount of creative verse and vision. In The Odyssey, for example, Homer describes the praises given by the hero, Ulysses, to the bard, Demodocus, for his singing of "the return of the Achaeans with a 11 their sufferings and adventures" 7 so wonderfully that $\mathrm{Jlysses}$ believes the bard "must have studied under the Muse, Jove's daughter, and under Apo110,"8 and U1ysses entreats Demodocus:

'Now, however, change your song and tell of the wooden horse.... If you will sing this tale aright I will tell all the world how magnificantly heaven has endowed you.'

The bard inspired by heaven took up the story at the point where some Argives set fire to their tents....9

The gift of creative inspiration was not conceived to be the gift of poets alone during this early epoch in Western civilization. Even the philosophers prior to Plato were inclined to attribute their philosophical insights, in fact their power of philosophical penetration, to a magical, divine tutelage or inspiration. For example, among the extant literary fragments of the pre-eminent Milesian philosopher, Parmenides (515-450 BC), are the opening lines of his poem, "On Nature," in which he described his enlightenment on a divine journey to the "goddess" who assured him, "Thou shalt inquire into everything."10 And she continued (Fragment 2):

'Come, I will tell you--and you must accept my word when you have heard it--the ways of inquiry which alone are to be thought.' 11 
From there followed the dictation to Parmenides of the treatise on the monistic philosophy of Being and the logical primacy of reason.

As illustrated in the examples of poetic and philosophic thought predating $\mathrm{Plato}$, the concept of divine inspiration was widely used to account for intellectual insight and poetic vision with relatively little scepticism; little else appears to have been available either to describe or to account for sudden and powerful breakthroughs of human thought or for transporting rhapsodic verse. A viable tradition of mystical inspiration as the well-spring of human creativity was deeply imbedded in the cultural tradition by the time Plato began his dialogues to commenorate his great teacher, Socrates, and to explore more systematically in writing than had yet been achieved the questions of honor, truth, social law, beauty, love, knowledge and reality.

Plato, himself an artist of the prose dialogue as well as a powerfully creative philosopher, appeared to be early inclined toward a rationalized acceptance of the traditional merit attributed to divinely gifted and inspired philosophers, statesmen, and poets, a 7 though all but the philosopher were noted to be often unknowing (theoretically and rationaliy) of what they spoke. 12 Plato's middle and late period dialogues, however, bring under increasingly critical examination this non-rational concommitant of inspiration and finally culminate in the unavoidable (for Plato's cognitive approach) divided image of creative artists who express themselves in highly affective but fundamentally inexplicable creations. 
Al though as Dodds suggests in The Greeks and the Irrational, the philosopher, Democritus (494-404 BC), must probably be credited with:

having introduced into literary theory this conception of the poet as a man set apart from conmon humanity by an abnormal inner experience, and of poetry as a reyelation apart from reason and above reason (italics mine),

Plato's systematic cognitive exploration of poetry and poets along with reality and knowledge led him to the most consequential identification of creativity with suprarational giftedness in early Western philosophy, and this inspite of the fact that Prato linked the "divine" inspiration of great creativity with the severe judgement of near madness.

From the beginning, Plato was equivocal about the merits of inspired creative expression, as evinced in his key middle dialogue, "Apology":

not by wisdom do poets write poetry, but by a sort of genius and inspiration; they are 1 ike diviners or soothsayers who al so say many things, but do not understand the meaning of them. 14

Along with such measured assessments, however, came eulogies in praise of poetic transports, such as:

...he who, having no touch of the Muses' madness in his sout, comes to the door and thinks that he will get into the temple by the help of art--he, I say, and his poetry are not admitted; the sane man disappears apd is nowhere when he enters into rivalry with the madman. 15

But even these praises do not preclude the coup de grace delivered to the free poetic spirit in the greatest of Plato's middle dialogues, "The Republic." It is in this dialogue that the irrational element in inspired poetic creativity is sentenced to exclusion from the state, though with full rites of garland and myrrh.16 Reason and 1 aw must 
prevail in the state under management by Plato's idealistic philosophy, and here emotion and the magical powers of the arts, including painting and music, must be carefully censored and controlled. The arts allowed in "The Republic" and later in the State under the organization of the "Laws" were limited to those which encouraged and exemplified order, vigor and rationality. Form, reason and skill took precedence over inspiration, lyricism and emotion:

...if you... allow the honeyed muse to enter, either in epic or iyric verse, not 1 aw and the reason of mankind...but pleasure and pain will be the rulers in our State. 17

Although even in his last monumental dialogue, "Laws," Plato acknowledged the elevated status of the creatively gifted and a certain reality to abide in their inspired works:

$\ldots$ for poets are a divine race and often in their strains, by the aid of the Muses and the Graces, they attain truth, 18 his convictions regarding the supremacy of ideal and logical truths caused him to devalue the rich emotional realities tapped by the creatively gifted and to distrust the irrational process, product and effects of inspired creativity. This is understandable in consideration of Plato's continuous emphasis on reason and logic as the controlling factors in the maintenance of the Republic. The "unreasoned" was neither the source nor the goal of the citizens' activities envisioned by Plato in the State ruled by philosopher kings.

Uitimately, history suggests Plato's partial rapture with inspired creativity marked civilization more deeply than did his doubts. The powerful articulation of suprarational inspiration as the fountainhead of superlative creativity bore over 20 centuries of 
aesthetic fruit, burgeoning most magnificently in the form of Neoplatonism in the great Quatrocento Renaissance in Italy.

\section{The Italian Renaissance}

Intoxicated with the rediscovered classical vision of man, the fifteenth century Italian cities teemed witin a vigorous urban life, spilling over with business and trade, humanistic studies, orations on the dignity of man, and tributes to the rich and the ruling in sculpture, fresco, oil painting and music. Under the sway of courtcentered schools and academies, particulariy the Platonic Academy in Florence, the Christianized Neoplatonism of such works as Marsilio Ficino's Platonic Theology, together with his translations of and commentaries on Plato and Plotinus ${ }^{19}$, imbued the invigorated citizenry with concepts of rational man as superior to other creatures in his power of creativity and self-governing which were conceived as nothing less than god-like.20 As Erwin Panofsky suggests, the Neoplatonic movement igniting in the Florentine Platonic Academy with Ficino's philosophical leadership caught on "like wildfire--a movement the impact of which can be compared, in range and intensity, only with that of psychoanalysis today." 21

Along with commentaries on and translations and interpretations of Plato, Plotinus and later Neoplatonic writings came waves of essays, treatises, and "orations" on the "nature of man," newly conceived in nearly miraculous aspect. Early among these was the work of the Florentine writer, Manetti, particularly his On the Dignity and Excellence of Man, which appeared in 1452, a decade before the estab- 
lishment of the Platonic Academy in Florence. Manetti dazzled the new intelligensia and literati with the vision of man as "endowed...with the qualities that he and his contemporaries valued most--beauty, creativity and inventiveness, wisdom, wealth and power."22 Manetti's focus concentrated especially on the works of man:

...all homes, all towns, all cities, finally all buildings of the world which certainly are so many and of such a nature that they ought rather to be regarded as the works of angels than of man.... Ours are the painting, ours the sculptures, ours the arts, ours the sciences, ours...the wisdom, finally...all discoveries, ours are all the different kinds of languages and literatures." 23

The Neoplatonic rapture with human potency of reason, morality, creativity and self-transcendence flamed through the consciousness of the time and reached its apotheosis in 1486 in Pico della Mirandola's Oration on the Dignity of Man. In Mirandola's Oration, man was pictured as created by God with "seeds pregnant with all possibilities" (emphasis added) 24 and fashioned to be "the free and proud shaper of (his) own being."25 In Mirandola's vision, man was conceived to be not only the creator of himself and his world through the potency of his knowledge of himself and of all things in himself, but to be, as he actualized himself in utter fullness of creation, "filled with the Godhead..., no longer (himself), but the very One who made (him)." 26

The convictions of Ficino, Manetti, Mirandola and other Neoplatonic thinkers and writers during this superlatively creative epoch reverberated in the lives and works of the artists--Botticelli, da Vinci, Fracastoro, Vasari, the "Divine"27 Michelangelo...--and promoted the outburst of splendor that was the Italian Renaissance. 
The shift in the conception of creativity here at the turn of western civilization from ancient and medieval times to modern was two-fold. First, and most importantly, the source of human creativity was retrieved from the external mystical site of the Muses and deities (with implicated problems of validation) and placed squarely within man himself as part of his own nature, his God-given endowment of ability. The wellspring of the effulgent creative outpouring of the Italian Renaissance was not an external God or touch of grace but the divine potency within the creative artists, architects, philosophers and writers themselves. The transporting effects of artistic expressiveness which caused Plato to exclude all but highly censored and controlled artistry from the well-ordered State, and which found little foothold in the contemplative Christian medieval period, were freed for a century in Italy and gifted the quatrocentro with unequalled creative achievements. During this unparalleled epoch, creativity was conceived as an internal capacity shared in varying degrees by a11, but amounting to "genius" 28 in a few overwhelmingly gifted individuals such as Michelangelo.

The secondary shift in the conception of creativity concerns the absence of serious hesitation before the non-rational aspects of the creative experience or product. The concentration in the Platonic dialogues on questions of epistemology, ethics and political theory led to the rejection of the irrational elements of the creative process and product. In contrast to the tumultuous Greek fifth and fourth century $B C$, the Renaissance and Quatrocento Italy enjoyed peace and burgeoning commerce in which ambiance the revival of the great 
classics produced monumental pride and trust in human individuality and personal development. The Renaissance, 1ike ancient Greece, breached the 1 imits of reason and sense-based knowledge in its aesthetic excesses, as can be seen in the passage from Mirandola's Oration quoted on page (11) above, but imagination's flights had become a significant part of man's own divine self-transcendence through the Neoplatonism that rationalized the Renaissance. The extravagances and excesses of the artist were cognized and even categorized as "madness" 29 during the Renaissance, but the creative expressions of the greats were accepted as the "heights" 30 of human achievement and as inspirations to all.

\section{The Eighteenth Century Enlightenment}

Under profound artistic influences from the two preceding centuries the arts were a central concern of most of the thought flooding Europe during the century (1700-1800) known as the Enlightenment. The prodigious outpourings of the Italian Renaissance (1400-1600) had quelled, but their influence was still burning deep in the European consciousness, as was the influence of the ancient classics which had inspired the Renaissance florescence. The period of El izabethan Eng1 and $(1533-1603)$ too had come to a close, but the products of its most spectacular progeny, Shakespeare and Milton, continued to hold cathectic power over continental and British philosophers, critics, and artists alike through the whole of the Enlightenment. The age of French Classicism, le grand siecle of 1600-1700, had produced the peerless dramatists, Corneille, Moliere, and Racine, along with the 
great classic painter, Nicholas Poussin, and a stream of brilliant critical writings.

In addition to the rich inheritances from the arts, the Enlightenment in Europe began under the influence of two major philosophical developments which were to direct its conceptualizations concerning creativity, talent, genius and inspiration. In England an empirical, scientific philosophy of experimentation had taken root by the beginning of the seventeenth century through the works of Sir Francis Bacon. By the last decades of that century, the scientific, observational flare had produced John Locke's empirical philosophy which centered on a new theory of mental processes, a psychology of associationism. At the same time, Sir Isaac Newton had begun restructuring conceptions of the physical universe and had delineated a potent two-stage scientific method beginning with observation, experiment and induction and from there proceeding to theorizing through resulting deduction. 31 Under the Baconian influence, the intellectual orientation of the Enlightenment in England began with a singly scientific, observational, experimental bias. In contrast, the bias of Cartesian rationalism embued the French critical work of the seventeenth century classicism with a predilection for logical method, rule, deduction and basic principles, and this coloration swept across the entire French Enlightenment and dominated the critical thinking of the first half of the English Enlightenment, as well.

Ultimately the strongest force in the eighteenth century theorizations concerning human creativity, however, came from a third quarter: revived Neoplatonism closely allied with Renaissance Neo- 
platonism through the philosophical dialogues and expository "letters" of Antinony Ashley Cooper, Third Earl of Shaftesbury.

At the outset of the Enlightenment, the conceptions of creativity, the arts, genius and the imagination that held the most sway were those of the French $\mathrm{Cl}$ assicists, most importantly of Boileau (16361711), "the law-giver of Parnasus."32 Carrying Cartesian rationalism deep into the fields of the creative arts, Boileau and other French Enlightenment critics held "rational knowledge" to be at the apex of artistic experience and designated "reason, logic and mathematics" as the methods by which to achieve knowledge and beauty in the domain of the arts. By purely deductive argumentation, the rationalists secured the arts fast to knowledge through the establishment of "imitation" as the "universal principle" of the arts and through the deduction of "rules" which would guide the artist to perfect imitation, beauty, truth. 33

Previously, Plato's reason-oriented philosophy of the arts had foundered, in part, on precisely the recognition of the imitative aspects of the arts. Due to the idealistic underpinnings of Platonic philosophy, significant reality was denied to material objects. Reality was non-material in Plato's vision; it was only secondarily reflected in the material world and therefore imitative arts could only provide a reflection of a reflection of the truth. Since, for Plato, the highest good was in the achievement of knowledge of reality, the result was that the arts could not be saved from devaluation in human experience. The fact that the most affective products of artistic creation were often conceived inspirationally and were not 
accessible to rational explanation removed them altogether from the status of the acceptable in human experience in Plato's view. For the Cartesian relationalists, however, the search for knowledge through "reason" was not a search for metaphysical essences but for applicable universal principles; imitation was the universal principle of all arts and "rules" could be established through deductive reason for the achievement of perfect imitation. Many questions were begged here, of course, but the "rules" devised and the works achieved were generaliy so satisfying to the sentiments of the times that they seemed to vindicate the theories.

Within the webwork of the theories, it must be noted, contradictions did emerge, but they were overcome by the sleight of hand of hidden assumptions. First, the experience of complete breakthroughs and brilliant originalities challenged the notion of the highest accomplishments' being attainable through "rules leading to perfect imitation and beauty." Aithough Boileau himself asserted that the rules were universal and there was no room for 1 icense, he finessed the implicit contradition in such poetic suggestions as the following:

It is in vain that a rash author thinks to climb Parnassus by dint of his versifying art. If he does not feel the secret influence of heaven, if the star which presided at his birth did not make him a poet, then he will always remain the victim of his meagre genius. For him Phoebus is deaf and Pegasus
stubborn. 34

"Versifying art" involved, of course, the very rules which were needed to arrive at "correctness." But something else was apparentiy needed: gift, talent, taste...? This "something else" is only variously named, not systematically uncovered in Boileau's or other Classicists' 
critical works. Clearly, this essential ingredient was acknowledged but was not reduced to a basic universal principle. Though the question was approached one way and another by the writers following Boileau, the frustratingly vague but apt French phrase, "je ne sais quoi" ("I don't know what") served as the final descriptor for that gift, talent, taste, special genius, as well as for the ingredient in the work that makes it original, sublime, a breakthrough. And, it was the vague "star which presided at his birth," rather than rules or capacities, that was implicitly left with the responsibility for the highest of achievements and effects. As Wittkower points out in his essay, "Imitation, Eclecticism and Genius," the Renaissance "conviction that artists are born not made" was paradoxically not even abandoned "by the most avid propagators of imitation and the rules," 35 the French $\mathrm{Classicists}$ of the eighteenth century.

Following Boileau, the critics Bouhours (1687) and Dubos (1719) began the first significant shifts in French Classicism away from the dominating current of pure rationalism in dealing with the processes and products of human creativity. In place of reason and deductive rules, they suggested the operation of a sensitivity, or "delicatesse," as the central guide in artistic creation and appreciation. Through this introduction of the experiential-emotional faculty, the qualities of "exactness and correctness" required by "reason and the rules" could be replaced by the psychologically more relevant quality of inexactness or indistinctness, which was conceived as inspiring the imagination of both the creator and the appreciator. Both of these 
new psychological factors, "delicatesse" and indistinctness, bore considerable aesthetic fruit. 36

of particular importance is the fact that, with the introduction of "delicatesse," the concept of a non-rational element of feeling began to play an active and productive role, along with the rational intellect, in the understanding of artistic creation and aesthetic enjoyment. After Dubos' aesthetic theory had elevated the experience of "being moved" to the status of the motive force in all human activity, with the experience of pleasure as its natural goal, the element of emotion became a central feature in theories concerning artistic creation and aesthetic appreciation. 37

Creativity achieved its most important treatment in the Enlightenment through the works of Anthony Ashley Cooper, Third Earl of Shaftesbury (1671-1713) in England. 38 As can be seen from his essays, which were collected together in the early 1700 's under the title Characteristics of Men, Manners, Opinions, Times, Shaftesbury accepted the logical part that learned technique and taste had to play in artistic creation and appreciation; however, he rejected both the radical rationalism of the $\mathrm{Classicists}$ and the empirical-psychological approach of his countrymen. Rather, he looked back to the Renaissance and the ancients for touchstones. Shaftesbury saw nature partially with the eyes of eighteenth century science, which was issuing forth new visions of dynamic interactive forces in nature, and partially with the eyes of an artist, as he himself was the author of creative philosophical dialogues. Beginning with the recognition of his own spontaneous and immediate experience of both nature and art (that is, 
experience without the mediation of reason), Shaftesbury developed an intuitional aesthetics which was rich in implications for philosophy in the Enlightenment 39 and the Romantic Age that followed.

The major breakthrough suggested by Shaftesbury's thought was the implication from his intuitional aesthetics that creativity was the sole technique for understanding the universe. This conception set rational knowledge aside as the crowning experience for man and substituted for it intuitional understanding. Where the rationalists had seen universal laws as basic to nature and had identified reason as the vehicle for gaining knowledge of those 1 aws and hence of nature, and where empiricists and scientists were observing, experimenting, and logically inducing general conclusions from which laws of nature could be logically deduced, Shaftesbury saw "nature itself in its deeper sense (as) not the sum total of created things but the creative power...."40 Thence,

Only the artist who constantly brings forth from within himself worlds in miniature giving them definite shape will be able to understand the universe as the creation of the same forces of which he is aware in his own creative processes. 41

An important implication for the conceptions developing around notions of creativity was the assertion that

the creation of the artist is no mere product of his subjective imagination, no empty phantasm; it is an expression of true being in the sense of an inner necessity and 1 aw. 42

This participation in the universal creative process is, for Shaftesbury, the quality and capacity of genius. With this definitive concept, Shaftesbury raised the idea of genius out of the previous vague associations with techniques, products and effects or special 
faculties of reason, sensibility, etc. In addition, Shaftesbury also made a clear contribution to the question of inspiration:

No poet...can do anything great in his own way without the imagination or supposition of a divine presence, which may raise him to some degree of (enthusiasm). Even the cold Lucretius makes use of inspiration, when he writes against it and is forced to raise an apparition $f$ Nature, in a divine form, to animate and conduct him.... 43

In the last decades of the eighteenth century, Shaftesbury's intuitional aesthetics, and particularly his concept of genius, were carried into fruitful new discussions by the German Idealist, Immanuel Kant. In his late work, The Critique of Judgement (1790), Kant defined genius in a decidedly Shaftesburian vein:

'Genius' is the talent (natural endowment) which gives the rule to art. Since talent, as an innate productive faculty of the artist, belongs itself to nature, we may put it this way: 'Genius' is the innate mental aptitude ('ingenium') 'through which' nature gives the rule to art. ${ }^{44}$

Here, the "inborn" status of genius and its specific identification with creative productivity are carefully articulated. In addition, the rationalistic "rules of art" are given secondary place to the rules that are naturally realized in the art work of the creative genius.

Kant's work also provides a further clarification of the concept of inspiration in its development after the Renaissance. Through his exacting analysis of concepts and human experience, Kant identified the source of the genius's ideas and originalities as internal to the nature of genius itself. Kant described the genius's experience of originality in these words:

... where an author owes a product to his genius, he does not himself know how the 'ideas' for it have entered his 
Where Shaftesbury before him had suggested the creative process to involve something of a participatory correspondence between the creativity of the artistic genius and the creativity of nature itself, Kant treated artistic genius as a more independent and specific natural endowment which has the power to realize its own final artistic ends through means it has realized in the process of creation. Kant's contribution here was to shift the emphasis in inspiration from an implicit interactive harmony with truths of all of nature and the universe to the internal natural genius of the artist alone. Kant treated inspiration so explicitly as within the realm of human mental experience and as non-rational at the same time that he appeared to be on the threshold of a conception of the "unconscious," which theories began to be developed in the decades following his work.

The intensity of Kant's idealistic treatment of genius, inspiration, and artistic creativity allowed his work to drive home the implication of nearly all previous theories of creativity that alluded to inspiration as the source of creativity since ancient times--that the creativity of genius cannot be taught or trained. Kant went beyond discounting the rationalist's inconsistently but frequentlyproposed thesis that creative perfection ("fine art") was attainable by the perfected application of "rules" in such passages as:

...we cannot learn to write in a true poetic vein, no matter how complete all the precepts of the poetic art may be, or however excellent its models. (Because)...no Homer or wiel and can show how his ideas, so rich at once in fancy and in thought, enter and assemble themselves in his brain, for the good reason that he does not himself know, and so cannot teach others. 46 
In the process of carefully articulating his conception of genius, Kant amplified the implications of the non-rational aspects of artistic creativity by setting artistic genius apart from intellectual scientific giftedness on the basis of genius's being nonrational. For Kant, the scientific intellectual gift could serve human knowledge and promote progress due precisely to its rational and communicable nature and hence it "could boast a ground of considerable superiority over those who merit the honour of being called geniuses (great artists)."47 It should be pointed out here that Kant actually was comparing artistic creativity (such as Shakespeare's) and scientific giftedness (such as Sir Isaac Newton's) on unequal grounds; artistic creativity was analyzed in its process of originating and creating, its "issuing forth the new," while scientific giftedness was analyzed at a later stage in its originating process, that of formulating and explicating the new insight(s) or cognition(s).

In contrast to the Renaissance, which attributed supreme value to creativity as a uniquely human process of aesthetic production and spiritual self-transcendence, the eighteenth century Enlightenment introduced the more experientially-based concepts of self-fulfilling pleasure and intuitive understanding of the universe's processes as the purpose and goal of human creativity. The Renaissance concept of genius as a "God-like" gift of creativity with which one is endowed at birth, if ever, was refined through the Enlightenment and was ultimately identified specifically with the process of artistic creation. The process of creation was generally unexplored by Renaissance thinkers, being conceived as a natural outpouring from the internal 
inspiration of the artist naturally endowed with the gift of creative expression. With the Enlightenment, theories of the creative process began to achieve some observational content as well as psychological depth. While inspiration continued, for the most part, to be conceived as essentially internal in origin and inexplicable, Enlightenment thinkers began to examine the artists' active participation in promoting excitement of the imagination and eliciting inspiration from within. Finally, the Enlightenment began to give systematic treatment to the role of technique and skill in the creative process, articulating the place of the learning and practice of rules and methods as well as of taste. "Genius" remained beyond the reach of instruction and teaching in eighteenth century thought, while the highly rational and teachable sciences, which were burgeoning in their midst, were ultimately elevated even beyond products of "genius," to become the new epitome of human achievement, products of pure intellectual giftedness.

In sum, the eighteenth century Enlightenment succeeded in netting some of the past's more powerful but indefinite concepts relating to human creativity and in bringing them into more systematic treatment and into closer contact with human experience. The observational, analytical, and psychological approaches of modern theories of creativity began to dawn there, and the modern "problems" in the field began to take initial form. 
The Birth of the Modern Era: 1900-1950

In the first half of the twentieth century, theories concerning human creativity began to crystalize around several core issues distilled from the past centuries; genius, imagination, inspiration, and the creative process were central topics of early research and analytical studies. The new psychological method of psychoanalysis and the underlying theory of the unconscious had been formalized by Sigmund Freud just prior to the turn of the twentieth century, and that work gave new dimensions to studies of creativity. Along with having direct impact on notions of inspiration and processes of creation, Freudian psychology and other psychological theories gave rise to systematic studies of personality, which became a focal point in ensuing creativity research. In addition, educational interests fomented around concepts of intelligence and creativity early in the century, and the developing data-based research methods were applied to the new field of educational testing which gained many adherents in the ranks of educators and psychologists interested in creativity.

The concept of genius, which had intrigued thinkers through the centuries, achieved its first modern treatment and defense in the 1865 landmark study, Hereditary Genius, by Sir Francis Galton. Appearing as it did in the wake of Charles Darwin's The Origin of Species, 1859, Galton's focus on the hereditary factor in genius was not altogether unprecedented; however, Galton's Introductions to the 1869 and 1892 editions of his work suggest that it was not universally wellreceived. Some of the points made by Galton in his Introduction to 
the first edition may indicate why the public reception was not entirely favorable. For example, he proposed:

to show in this book that a man's natural abilities are derived by inheritance, under exactly the same limitations as are the form and physical features of the whole organic world. Consequently, as it is easy...to obtain by careful selections a permanent breed of dogs or horses gifted with peculiar powers of running, or of doing anything else, so it would be quite practicable to produce a highly-gifted race of men by judicious marriages during several generations. 48

Nevertheless, the study had its impact and was followed in later decades by similar studies; the notion of hereditary influence on intelligence and creativity has currency in some studies even in the closing decades of the twentieth century.

Galton's study focused centrally on 415 illustrious men and their familial relationships to other eminent individuals through a study of public evidence of reputation and achievement as well as of biogranical records. Although his study was, at base, anecdotal, Galton accomplished a prodigious feat of documentation and statistical analysis of the historical data, developing the method which has come to be known as "historiometry."49 The result was a work which demonstrated significant correlations between the eminent figures central to his study and a familiar background of eminently gifted individuals. Through his study, Galton contributed the first documentation of genius as not only possibly a hereditary trait, but as closely associated with creativity along a wide spectrum of human endeavors. Specifically, Galton linked genius with originality, creativity, and productivity, and assumed that the exceptional giftedness of genius 
results almost unfailingly in reputations of eminence and culturally recognized achievements. 50 Galton's study also provided an array of references to specific characteristics, tastes, talents and experiences of the geniuses he researched in depth, thus providing the precursor to modern studies of talent, creativity, and giftedness based on character or personality traits and on environmental influences.

The study of genius took a decisive turn away from the broad and subjective connotations it had carried, from the Renaissance up through Galton's work, primarily as a result of the development of intelligence instruments in the early 1900s. By 1920, the standard form of the IQ test had been established. 51 With the apparent means of testing and measuring intellectual capacity, "genius" became identified with "high IQ" and studies began to center on the specific ability to achieve high scores on IQ tests, most commoniy the Stanford-Binet test.

Following Galton, in 1921 Lewis Terman began a 25-year longitudinal research study of genilus focusing on 1000 second to twelfth grade school children who tested in the upper $1 \%$ of the general school population in California on the Stanford-Binet. Terman's study was very broad-based, as it researched multiple aspects of influences on and performances of these young geniuses, from prenatal conditions, through early health, sociability, family, and education, to lifestyle and achievement in adulthood. Carrying out this research across such a broad spectrum and over such an extended period of time allowed for the inclusion of many of the aspects of the subjects' lives and leanings not directly associated with or limited to IQ. For example, 
personality profiles of youths were gathered through testing and gleaned from teacher and parent reports, performance and achievement across all curricular areas were tracked, and family background and environment were studied in depth.

Ultimately, Terman's work served to strengthen the growing tendency in education to focus sharply on intelligence as measured by the IQ test and to identify "genius" with exceptionally high IQ scores. In addition, Terman's research bore out the long-standing conclusion "that superior achievement tends to run in families." 52 The breadth and balance of his study, however, brought important collateral aspects of genius and eminent achievement into modern focus. First, such traits as extreme curiosity, independence of judgement, unusual interests, and versatility, 53 as well as a tendency to great enthusiasm, 54 were identified as typical of the highly intelligent. The concentrated attention on "traits of genius," including psychological and behavioral traits, and on environmental influences on genius, was particularly exemplified in the second volume of Terman's study, The Early Mental Traits of Three Hundred Geniuses: Volume II of Genetic Studies of Genius, by Catherine M. Cox, 1926.

Terman's research contributed not only to the modern definition and description of genius, but also brought to light several issues of importance to modern education. First, teachers' tendencies unwittingly to misjudge or to discount the highly gifted on the basis of unusual behaviors and traits 55 were noted and explored. Second, countering the common myth of genius as often physically sickly and psychologically unstable, 56 Terman's work provided a profile of gifted 
individuals "slightly superior" 57 to the norm physically and less likely, over all, to experience significant mental or emotional crises. 58

Further, in Terman's work, creativity was continuously implicitly associated with genius. Initially, the study reported typically "very high" scores in the areas of art and literature as well as in science for the young geniuses in addition to a family background of eminent individuals of whom one third received their distinction for original, creative work. The follow-up study of the subjects noted that, by "mid-life," this group had authored 2000 scientific and technical papers and articles, 60 books and monographs in science as well in the liberal arts, 33 novels and 375 short stories and plays, 60 essays and 265 articles on miscellaneous subject. In addition, 230 patents had been granted to subjects in this study and thousands of radio and TV scripts had been produced by them. 59 The achievements of the subjects proved to be highly creative as well as professionally significant.

The questions and curiosity concerning the causes of genius, particularly hereditary and environmental causes, continued after Terman's fruitful study, giving rise to a continuous flow of research in these areas. The central focus of identification for research on "genius" remained, in general, the specifically quantifiable IQ measurement of intellectual giftedness, amounting to a tautological definition of genius which still prevails at the close of the twentieth century. As forthcoming research on creativity was to make clear, this dominance of emphasis on reason- and logic-centered intel- 
ligence caused a tacit disregard of creativity in the field of education.

Just prior to the conclusion of Terman's study, a major review of research on questions of genius was published in 1940--Genius in the Making, by Herbert A. Carroll. In this work, Carroll underscored the conclusion of Galton and Terman, still theoretical albeit statistically demonstrated, "that genius runs in families." 60 Following Terman and the publication of most of his research, Carroll was able to synopsize from that momentous study and other smaller studies to develop the beginnings of a taxonomy for the field of study of giftedness or genius. Of special importance in Carroll's review is his focus of serious and equal attention on artistic giftedness in the context of studies of genius and IQ. 61 Carroll also brings attention to the work running parallel to research on genius and IQ concerning creativity and its measurement, reiterating the lack of correlation between creativity and IQ and noting the continued paucity of objective or validated tests for creativity, ${ }^{62}$ although some prelininary tests were being researched.

Carroll's work, in the end, appeared to be a strong defense for both the intellectually and the creatively gifted. Although not advancing questions of the actual relationship between intelligence and creative or artistic giftedness, Carroll emphasized an underlying point of considerable significance concerning the environmental encumbrances to the exceptionally gifted in America:

There has developed in America, side by side with an enthusiasm for success stories, a cult of mediocrity. This is everywhere apparent in American social and political structure and, unfortunately, in the educational system. 63 
By the late 1940s, "genius" had become synonymous with exceptional levels of abstract intelligence as measured by IQ tests and, due to the recognized lack of correlation between intelligence test scores and known or assumed creative capacity, the concept of "genius" had formally lost its association with creativity. This lack of correlation had been noted as early as 1898 by Dearborn in his study of the responses of Harvard students to inkblots in a test of imaginative powers. He found that "some of the poorest records were made by students of the decidedly intellectual type."64 In 1916, Laura Chassell reported replication of Dearborn's results, finding that, using her newly developed "originality tests," subjects' "performance on the IQ tasks bore relatively little relation to performance on the creativity tasks."65 By 1922, R.M. Simpson could sum up the failure of the dominant psychological IQ tests to account for creativity in human intellection in these words:

Tests devised to ascertain either native intelligence or acquired knowledge are certainly valuable.... (However), there are no elements in them to extract from the mind of the individual his powers of creative productivity and his tendencies toward originality....66

The discontinuity between intellectual capacity as measured by IQ tests and creative capacity continued through the first half of the twentieth century. As Getzels and Jackson summarized the situation:

(By 1946) the casual observation by Dearborn in 1898 had become a commonplace research finding--giftedness in intelligence and giftedness in creativity were by no means synonymous. 67 
While creativity had lost its explicit connection with the highly sought status of "genius" in the first half of the twentieth century, interest in filling the testing gap had produced some preliminary originality tests. 68 At the same time, serious study was focusing on the unique processes and personalities which produce creative works.

The process of creativity had come under increasingly close scrutiny following Henri Poincare's presentation of his own creative process in The Foundations of Science in 1915. Poincare recognized four basic stages or phases in his process, beginning with conscious work on a hard problem, after which rest was taken. When work was resumed, a period of fruitless endeavor would generally ensue and then "all of a sudden the decisive idea presents itself to the mind."69 Finally, after the "inspiration," conscious work was resumed for formulation and "verification."70 In 1926, G. Wallas' work, The Art of Thought, presented a four-stage breakdown of the creative process very similar to Poincare's: (1) preparation, (2) incubation, illumination, and (4) verification. 71

These stages in the proposed process of creativity became the focus of a research study in 1937 by Catherine Patrick in which she assembled 50 professional and 50 non-professional artists and observed their processes of sketching pictures. While they sketched, the subjects were encouraged to express their thoughts aloud and to answer questions that were asked. Patrick's study confirmed a generally four-stage creative process similar to that outlined by Wallas to take place in the sketching of pictures, most decisively with the profes- 
sional artists, but the stages were not followed quite so sequentially as $W a 11$ as suggested. 72

The study of creativity in its dynamic process through the first half of the twentieth century provided increased understanding of some of the previously more mysterious aspects of creativity. Seen from the perspective of a somewhat sequential process where beginnings tend to be shrouded in vagueness and imprecision and where development leaps ahead once insight breaks through, the creative process appeared somewhat more rational, especially as the same process seemed to apply to both artistic and scientific enterprises.

Increasingly during this period, processes of artistic and scientific creation were being sensed or seen to be similar. Not only did Poincaré, a mathematician, outline a creative process naturally followed also by artists, but in his work, Art and Experience, 1934, the philosopher and educator, John Dewey, analyzed in detail the process of creativity in thought which occurs irrespective of its field of application. In brief, according to Dewey, creative insight takes place when, through interest in a problem and a natural process of incubation, conscious intuition, like "a flash of revelation," 73 brings the unknown and known into sudden harmony of recognition. Dewey described this intuition as "neither an act of pure intellect in apprehending truth (i.e. logically or scientifically) nor a...grasp by spirit of its own images and states (i.e. artistically),"74 but rather as a natural mental process of connecting the old (known) with the new (unknown), which is operative in any field of conscious interest. Here, inspiration or illumination received a very rational and dynamic 
description, and the still inexplicable mechanism of the flash of creative insight was recognized as being of something of the same nature for both scientific and artistic creation. The difference Kant had assumed to exist between the two processes (at different stages) was here, at the stage of creative inception or insight, resolved, but differences between the two creative processes on other levels remained to be worked out.

The framework of the stages of the creative process, together with the psychological and biographical data generated in the research on genius, provided a vantage point from which investigators could focus more closely than ever on the creative individual at work and in his or her development. The creative personality became, in the early twentieth century, a new subject for investigation by researchers. Such investigation could draw to itself theories and starting points from the emerging fields of psychology and psychoanalysis as well as draw together the tangential or fragmentary information brought out in studies of genius and in the literature on and by creative individuals through the centuries.

The psychology of the creative personality began to take concrete form as early as 1928 with Alpert's article, "The Solving of Problem Situations by Pre-School Children," in which he reported:

The arousal of insight and its consummation in a practical solution are favored by emotional, temperamental, and mental factors--those which in effect constitute the total personality. 75

The classic work, The Road to Xanadu, by J. L. Lowes, in which Coleridge's personality and creative process are described in some detail, 
appeared in 1930,76 and The Psychology of the Inventor, by J. Rossman, followed in 1931,77 detailing inventors' processes and personality traits on the basis of answers to questionnaires designed for the study. The psychologist, Anne Roe, began her concentration on creative personalities with research into the personalities of artists, published in 1946, and then into scientific creative personalities, published in 1949 and early 1950. In her research investigation of the distinguishing characteristics of eminent artists and scientists, Roe's main conceptions centered on the intensely driven nature of the whole creative personality, the whole person, in the creative process. 78 Although her work was closely bound to objective research procedures, an anecdotal and biographical quality characterizes Roe's psychology of the creative personality as it did most of the early work in this new area of psychological investigation.

In 1949, the creative personality became one of the focal points of research at the newly established Institute of Personality Assessment and Research (IPAR). IPAR was designed to follow objective and well-structured assessinent procedures to research the personal lives and careers of highly effective people and to investigate the question of how such people are produced in our society. 79 Its derivation from the research of the first half-century is obvious, and its specific inclusion of creativity and creative people is understandable.

As the research on creativity at IPAR was broken into four parts (the creative product, the creative process, the creative person, and the creative situation), the psychology of the creative person received only a portion of the initial efforts of the Institute in 
researching creativity; however, with the use of such comprehensive instruments as the Minnesota Multiphasic Personality Inventory (MMPI), which became available in 1943, and other objective tests and procedures at the Institute, a major effort was inaugurated to research the psychology of the creative person in depth.

Although, according to Getzels and Csikskentmihalyi, between the years 1900 and 1950 "creativity had only a small constituency and no market, "80 the present review does suggest that the study of creativity was gaining ground on several fronts during this period. While creativity was technically dislodged from its traditional position at the center of the emotionally-toned concept of "genius," it was kept very much in view by two aspects of the new historiometric and psychological research into "genius"--1) a significant portion of the subjects researched were illustriously creative, and 2) psychologists using the new intelligence tests became quickly sensitive to the possibility of a significant limitation of the instruments since they appeared to be "creativity-blind" and therefore substantially limited. Further, research into genius had amassed large collections of incidental psychological data concerning creative individuals, which ultimately helped to fuel the new thrust of psychological investigations into the creative personality. Finally, the question of the creative process itself, which had been tacitly central to the concerns about creativity since ancient times began to be systematically explored early in the twentieth century. By mid-century, many of the basic features of creating had been generally outlined and demystified, and relationships between scientific and artistic creativity 
began to emerge, promising much for future concepts of intelligence and human creativity alike. The first half of the twentieth century was not explosive with breakthroughs in "creativity theory," but the progress in theory and application was steady and substantial. This period delivered many traditional concepts about creativity in revised and clearer terms to the second half of the century, and it delivered new methods, perspectives, instruments and subjects to enrich the research and other investigations into creativity for the ensuing decades. 
CHAPTER I I I

CREATIVITY AND EDUCATION: 1950-1985

The researchers in the field of creativity received a powerful spur to action in 1950 by J.P. Guilford's landmark Presidential Address to the American Psychological Association:

The neglect of this subject by psychologists is appalling. The evidences of the neglect are so obvious that I need not give proof. But the extent of the neglect I had not realized until recently.... of the approximately 121,000 titles 1 isted (In "Psychological Abstracts") in the past 23 years, only 186 were indexed as definitely bearing on the subject of creativity.... In other words, less than two-tenths of one percent of the books and articles indexed in the abstracts for approximately the past quarter century bear directly on the subject. 81

The areas of creativity that had assumed central importance in the research during the first half of the twentieth century began increasingly to appear as the focal points of major research efforts in articles in professional and education journals after 1950 . The investigations since 1950 have focused most vigorously on the creative personality or "disposition" 82 and creativity tests, with significant work also centering on the creative process and the role of schools in fostering creativity. As Thurstone predicted in 1952, "In starting formal studies of inventive talent we may have to explore widely before finding the clews (sic) that may eventually enable us to identify such talent at an early age." 83 


\section{The Creative Personality}

Personality research, following the extensive explorations by Anne Roe and L.M. Terman in the first half of the twentieth century and the establishment of the Institute of Personality Assessment and Research (IPAR) in 1949, began with strong presentations of findings accumulated by such researchers as Anne Roe, Frank Barron and Donald w. Mackinnon. Both eminent artists and scientists were observed, tested, interviewed and assessed by these investigators with resulting identification of significant personality and behavioral tendencies in common among them. These initial objective and in-depth visions of creative personalities and their processes provided a rich background against which to view the creativity-related theories of psychologists such as Carl Rogers and Abraham Maslow as well as the observations being collected in the school setting of creative children and children's creativity.

of particular importance in the early stages of creative personality research was the identification of the somewhat anomalous behaviors and psychological sets quite common to the notable creative individuals under study. These included such characteristics as introversion, self-assertiveness and dominance with attendant selfassuredness, unusual divergent thinking patterns, independence of judgement, complexity of personality, humor and playfulness, nonconformity and imperviousness to social pressure, and dedication or drivenness of personality. 84 The personality characteristics of crea- 
tive individuals relate to important issues concerning the creative person, education, and society at 1arge.

First, as educators and psychologists have pointed out 85 , these personality characteristics and the others documented as falling along side them in the personality profiles typical of creative people are logically necessary components of a personality which can break with established traditions and views to see and give expression to the entirely "novel." The creative conceptualization must follow unusual by-ways with concentrated attention and involvement sufficient to resist the pressures and the temptation to "stick, after all, with the accepted and the acceptable view." As Carl Rogers suggested:

...the more original the product, and the more far-reaching its implications, the more likely it is to be judged by contemporaries as evil. The genuinely significant creation, whether an idea, or a work of art, or a scientific discovery, is most likely to be seen at first as erroneous, bad or foolish. 86

The tendency in the research to identify and isolate the anomolous characteristics of creative personalities has laid the groundwork for a possible atomization of the complex psychology involved, especially when "identification" became a dominant issue, but the major trend in the field of psychology dealing with creativity has been to emphasize the interconnectedness of these traits and "the total personality of the originator" 87 underlying these related traits. The creative individual must follow his or her own star, unusually alone and often in the face of severe judgement, even ostracism, in order to produce the authentically new breakthrough. 
Second, peer-pressure is a central force in the daily life of the student from intermediate grades through college, as nearly all graduates of educational institutions in the United States know from personal experience. The effects of this condition have generally been rather readily accepted as "good socialization-training" by educators, parents and social-psychologists by and large, until recent1y. The negative effects that the school-years' group pressure might have produced have not been a very widely-recognized phenomenon, and most adult efforts to ameliorate stress-producing peer-rejection situations have involved either attempting to bring the group under central teacher-control or trying to "help" the rejected student adjust himself or herself to the peer-expectations, or both. As Torrance pointed out, "Unusual or original ideas are common targets for peer pressure to conform, "88 and "...children are taught early the harsh consequences of divergent behavior, even outstanding performance in many areas of life." 89 The "socialization-training" may be heavily counterproductive, it appears. According to Crutchfield, the training may be in self-abdication:

Conformity, involving loss of self-reliance, undermines the person's creative powers by weakening his trust in the essential validity of his own processes of thought and imagination.... (It) inhibits the person's ability to sense and grasp basic reality, and the loss of this contact with reality is fatal to creative thinking. In short, conformity tends to destroy creativity....90

As a consequence, school is often neither an academically "totally successful" nor personally "terribly satisfying" experience for the highly creative person, as the research on eminently creative individuals suggests. 91 
Third, as suggested by Ziegfield in 1961, "... strong trends toward conformity and uniformity are increasing in our culture." 92 Those trends have continued to increase. The conclusion of Toynbee in 1962, however, states a significant implication of Ziegfield's observation: "To give a fair chance to potential creativity is a matter of 1 ife and death for any society." 93

This early direction in the mid-twentieth century psychology of creativity, focusing on the multiple, often uncommon, facets of the creative personality and behavior, provided a solid foundation for further, frank assessments of the creative adult which could be, to a degree, extended to the student in school. The field was already in full stride of development when Sputnik was launched in 1957, galvanizing all of America to the needs for more creativity in the nation, particularly in the sciences. Creativity began to be given new importance in education. 94

While initial tests of "creativity" were still in preliminary and uncertain form, 95 research psychologists proceeded with studies to identify and assess the personality and behavioral correlates of recognized creative adults. In the educational setting, parallel observational investigations were brought to focus on school children. Finding behavior and personality patterns among potentially creative students similar to those of ultimately creative adults, educational psychologists were able to give initial outlines to some of the possibilities, needs and problems facing schools with respect to creative children. The tentative "profile of creative students" began to achieve form and "reputation," as it were. The spontaneity, noncon- 
formity, independence, impulsiveness and humor of potentially creative students were leading educators to the perception that creative students could be viewed by teachers and peers as "obnoxious," 96 and "difficult to get along with," 97 and were "often not easy to tolerate."98 observations were, therefore, not surprisingly, suggesting that "creative behaviors" were being suppressed in the classroom setting. 99

At the same time, the professional and public interest in creativity and its cultivation for the nation's welfare were mounting:

1954-- Not only individual maladjustment and group tensions but international annihilation will be the price we pay for a lack of creativity. 100

1959-- The most urgent reason (for the interest in increased creative performance and the nature of creativity) is that we are in a mortal struggle for the survival of our way of life in the world.101

Razik summarized the American awakening in the late 1950's:

However creative our scientists and engineers had been previous to Sputnik, they would need to be more creative in the future; their numbers would have to be greatly increased.... Research on creativity became legitimized as a properly serious concern of the military, government and industry. 102

The studies centering on creative individuals were exciting "a good deal of interest and curiosity"103 by the 1960's. The following two decades saw the proliferation of "creative personality" research and assessinent by psychologists, and the application of their findings by educators to the understanding of creative students. As the diverse personality characteristics correlated with creative adults began to be absorbed by researchers and theoreticians and applied in educational research in the schools, the understanding of the creative 
personality deepened. The highly noticeable and important trait of "nonconformity," which could be difficult to distinguish from a merely conflictive reactionary tendency, for example, was analyzed carefully by Pepinsky; 104 and two forms of nonconformity were distinguished: the productive and the non-productive. The utility of this analysis can be seen, especially when coupled with Pepinsky's suggested strategies for turning authentic but non-productive independent-mindedness into "productive" nonconformity for the good of all. Its utility in the school setting can be easily assumed in light of the article by Torrance which appeared the year before and which emphasized a crucial implication for schools of the growing understanding of creative children's temperament and personality: "The school's job is one of helping the highly creative child to learn to be less obnoxious without sacrificing his creativity." 105 Another example of the creative personality's being more deeply fathomed is seen in the work of Robert C. Wilson. In an article in Education, 1960, Wilson drew from the extensive research on eminent scientists to neutralize the longstanding social and educational contention that to be highly successful an individual needs to be "well-rounded." He notes, "...to be a highly productive or creative adult, one cannot be well-rounded. One must devote a very great amount of time to one area of interest."106 In the end, "interest" must be acknowledged as the basis of "encounter" froin which all genuine creativity flows, according to May. 107 Another myth-dispelling point concerning high-level creativity brought out by the personality research since 1950 was the fact that evidence of potentially great creativity in a field of work is often 
not apparent in the creative individual's early years. As Hudson noted, "...nothing of Darwin's previous development could possibly alert us (to his outstanding talent). It simply is not the case that psychologists, even with the benefit of hindsight, can detect the signs of his dormant gifts."108 similarly, Roe determined from her study of 64 eminent scientists that such creative persons do not necessarily decide on careers in science "just as a matter of always following a natural talent. (But rather, in fact,) the most important factor in the final decision to become a scientist is the discovery (often late in college years) of the joys of research."109

As a further example of the extensive penetration of the work in the psychology of creativity, Torrance followed leads from the recent psychological studies and his own education-based research and concluded that the development of creative capacity was important not simply for society's or the nation's "survival"110 but for the healthy development of the individual's personality: "I believe there is little question that prolonged, enforced repression of the creative desire may lead to actual breakdown of the personality."111 Another dimension was added to this insight by Toynbee: "When creative ability is thwarted, it will not be extinguished; it is more likely to be given an antisocial turn."112

\section{Assessment of Creativity}

At the beginning of modern creative personality research, a number of psychological testing instruments were available for objective assessment and data collection, 113 such as preliminary versions 
of the Minnesota Multiphasic Personality Inventory (MMPI), Gough's "Adjective Check List," Strong's "Vocational Interest Test," the California Psychological Inventory, and the classical Rorschach Psychodiagnostic and Thematic Apperception tests.114 In contrast, a few assessment instruments for "creativity" as a special capacity or aptitude were in preliminary form, but were not yet certain or validated. 115 In his Presidential Address to the APA in 1950, Guilford summed up, at once, the paucity of instruments to measure or identify creative ability and the long-hypothesized difference between strictly intellectual abilities as measured by standard intelligence tests and the creative capacities.

Tests designed to measure intelligence have fallen into certain stereotyped patterns, under the demands for objectivity and for scoring convenience. I do not now see how some of the creative abilities, at least, can be measured by means of anything but completion tests of some kind. To provide the creator with the finished product, as in a multiple-choice item, may prevent him from showing precisely what we want him to show; his own creation.... What I am saying is that the quest for easily objectifiable testing and scoring has directed us away from the attempt to measure some of the most precious qualities of individuals and hence to ignore those qualities. 116

In other words, we must look well beyond the boundaries of the IQ if we are to fathom the domain of creativity. 117

First suggested as early as 1922 by R.M. Simpson, 118 the possible creativity-blindness of standardized intelligence tests and the hypothesized independence of creative and intelligence (IQ) factors encouraged the development of distinct creativity-assessment tests. Included in Guilford's 1950 Address to the APA were suggestions for test-tasks to measure nine factors which Guilford initially hypothesized as important in creativity: sensitivity to problems; 
fluency; novel ideas; flexibility; and the abilities to synthesis, analyze, reorganize or redefine, to handle complexity, and to evaluate. 119

Guilford's factors and his suggested test-tasks figured importantly in the development of the first creativity test batteries by Torrance and his colleagues at Minnesota (1961). Where "immersion" in written information about recognized creative persons provided Torrance and his associates with reality-relevance guidelines, Guilford's work provided material which could be directly adapted for use in the initial Forms $A$ and $B$ of the Minnesota Tests for Creative Thinking. 120 Form $C$ (Test of Imagination) was then added, involving a "modify the toy to be more fun" task for younger children.

By 1962, Torrance and his colleagues were aware of a need for a broader scope of test tasks and a wider range of behavioral observations to gain a more complete view of elementary school children's creativity. Their battery was revised accordingly to include a greater variety of stimuli and a larger number of the senses and to allow for wider ranges of behavioral observations in the seven verbal and three figural tests.121 In their revised forms, the Torrance Tests of Creative Thinking were designed to measure a broad spectrum of creativity-related factors, including divergent-thinking factors, elaboration and originality, curiosity, sensitivity to problems, complexity and communication. 121

Torrance's contribution to filling the gap in creativity assessments has been considerable, if not without limitations. Gowan and Demos describe Torrance as "the prime developer of creativity assess- 
ment in school children, and the foremost champion of measures to increase creativity in the classroom." 123

Though the Torrance Creative Thinking Tests remain the most comprehensive creativity test battery and the most widely used in schools, other aptitude-centered creativity tests have been developed and used in the educational setting. Most important among these is the Wallach and Kogan Battery $(W-K)$ which is based on Mednick's conception of the creative process as the association of ideas initially quite remote from one another. 124 The Wallach and Kogan Battery is nearly as widely used in schools as the Torrance Battery, and its contents parallel the Torrance Battery somewhat closely both in involving verbal and visual components and in including similar subtests, such as Alternate Uses $(W-K)$ /Unusual Uses (Torrance) and Visual Content Tasks (W-K)/Incomplete Figures (Torrance).

The use of the Torrance and the Wallach and Kogan batteries has been wide enough that considerable data have been collected regarding their possible validity and/or predictive power. Although the authors of each of the batteries have themselves concluded that validity and predictive power can be asserted for their tests, uncertainties still abound. In 1972, Crockenberg asserted that the validity evidence for both was "clearly inconclusive," 125 and there are multiple questions challenging these tests.

As with all tests addressing "creative capacity," the Torrance Creative Thinking Tests and the Wallach and Kogan Battery aim at measuring key aspects, if not the whole, of "creativity" as identified by the conceptualizations of the authors. For the Torrance Tests, the 
central feature of creativity was envisioned to be divergent (unusual) thinking in forming ideas or hypotheses to solve sensed or stated problems.126 Although expressed quite differently, the basic concept of "creativity" behind the Wallach and Kogan Battery is generally similar; the wallach and Kogan thesis centers, as stated above, on the association of ideas remote from one another in the normal thinking pattern where the association is not only unusual but also appropriate for solving the problem. 127 In general, then, both the unusualness of ideas, as measured by the rarity with which those answers are given, and the appropriateness of ideas to the task's solution, as judged by individuar assessment, serve as the basic measurements of these two batteries.

While it may be that divergent thinking or associational thinking are the essential characteristics of processes of creative functioning, it is still necessary to determine if the several factors that are isolated and measured by the tests are the discrete elements which may account for or predict real-life creativity. Since these instruments have been used primarily with school children, the question of the validity of the measurements for real-life creativity has been somewhat distant from demonstration and this constitutes one of the major obstacles to their being accepted as clear indices of creativity. Secondly, the distinctness of the factors measured from any aptitude other than "creativity" has been difficult to demonstrate conclusively. Since there has been fairly wide acceptance of the long-standing hypothesis that standard intelligence tests and achievement tests, which are used to the saturation point in education, do 
not measure aspects of creative potential, 128 nowever, the utility of separate creativity measures has been long assumed; the question in the aptitude-testing atmosphere is only whether the currently available creativity measurements do, in fact, measure creativity factors, as such.

In attempting to address the question of predictive validity, Torrance undertook a 12-year longitudinal study using his Creative Thinking Test which, according to the author, resulted in indications "that the performance of high school students (on the tests) is related significantly to their adult creative achievement;"129 however, his findings have been variously challenged. Most significantly for the question of the tests' predictive power is the indictment that the "criteria" which Torrance used to assess the students' later adult creativity are actually characteristic of any typical, well-educated high-IQ adult.130 Further, the value of associating divergent-thinking as assessed either during school years or later with adult creativity has been challenged; for example, Mansfield and Busse concluded that "few divergent thinking tests show evidence of criterion-related validity (in the case of adult professionals)."131 In addition, the direct relationship between divergent-production test factors and "creativity" has been seriously questioned, for example by Kogan and Pankove, 1974, 132 among others.

Finally, the discriminant validity of the Torrance Tests (their demonstration of measuring discrete "creativity" factors independently of other factors such as those in intelligence as measured by traditional intelligence tests) has been found by Torrance only above the 
IQ level of 120.133 Where the tests are independent of IQ's at levels below 120, they have shown no underlying interrelatedness among subtests which could demonstrate that one identifiable capacity (i.e., creativity) independent of intelligence was measured across the subtests. 134

While these challenges to the validity of the Torrance Creative Thinking Tests should seriously undermine any complete confidence in them, they are still widely used 135 and thought to show "sufficient evidence of reliability and validity" 136 to be used as measures of divergent-thinking. As emphasized by Treffinger, 137 Guilford, 138 Kogan139 and others, however, divergent thinking is itself not synonymous with creativity; many other functions, in addition to divergent-thinking, make their contributions, ultimately, to creativity.

The Wallach and Kogan Battery has faired rather better than the Torrance Tests in validation studies. At least, the $W-K$ Battery has been found to exhibit a high degree of relatedness across its subtests, indicating that "a fairly unitary phenomenon" is being measured. 140 The battery also appears to exhibit a greater relative independence of the measured "phenomenon" from intelligence as assessed by standard IQ measurements. 141 With respect to predictive validity, however, though a study conducted by Wallach and Wing, 1964, appeared to suggest predictive validity for the battery, 142 Feldman's review of the study found the results to be "inconclusive"143 due both to technical problems within the multi-facted study and to the limited range of subjects used. 
Other instruments used to measure creative potential of students include Guilford's measures of divergent thinking144 and Getzels and Jackson's creativity battery.145 As Crockenberg has pointed out, however, these creativity-related instruments have much in common with the Torrance Creative Thinking Tests and hence need not be discussed separately here.

A test which, unlike those mentioned above, relies almost exclusively on visual stimulus items and their perception is the Physiognomic Cue Test, developed by Morris Stein, 146 which can be used with individuals of any age as it is relatively free of academic or verbal thresholds. As interesting as this instrument may be for assessing creative sensibilities, it does not seem to tap any of the functions operative in creativity beyond immediate perceptual and emotional responses and hence is too narrowly limited for wide use. Similarly, the often-noted Barron-Welsh Art Scale (Revised 1959) relies heavily on visual stimulus items and, while correlating highly and regularly with adult creativity, does not present itself as a test of creativity such as might be useful in public school settings. 147 Further, the widely used and researched Remote Association Test (RAT), developed by Mednick, 148 has significant limitations for use in education due specifically to its reliance on verbal stimuli requiring a high concentration of information to be available in order for there to be meaningful responses. The RAT has been used extensively with adults at IPAR and occasionally in school settings at higher grade levels where the necessary associative clusters of concepts or words have more likely been attained. 
In summary, then, it can be seen that education does have at its disposal today several instruments for possible use in identifying creative potential in students, but both predictive and discriminant validity remain uncertain. The assertion of Kneller in 1965 that "no reliable tests have yet been devised to measure individual creative qualities" 149 was reiterated and elaborated upon by welsh in 1975:

...the search for an easily administered test of creativity that is independent of traditional tests of intelligence has not been successfully demonstrated by those working within a cognitive framework. 150

The situation remains the same today with respect to instruments which can reliably identify an aptitude for creativity in student processes or behaviors.

The modern consensus is beginning to coalesce around an expanded conceptualization of creativity as a multi-faceted capacity involving both divergent thinking and crystalized and fluid intelligence factors, with additional contributions from a wide range of personality factors. 151 while it has long been argued that standardized intelligence tests measure only a limited range of cognitive abilities (six to eight of the 120 abilities isolated in Guilford's Structure of the Intellect mode1) 152 and hence provide an incomplete picture of students' abilities, particularly omitting the "creative areas, "153 the relevance of intelligence to creativity is by no means obviated. Torrance, Getzels and Jackson and others have demonstrated that IQ levels and creativity levels (as measured by appropriate available tests) are not strongly correlated, particularly above the 120 IQ threshold;154 however, clearly "a certain amount of intelligence is required for 
creativity."155 Further, though current creativity-related instruments do not give evidence of providing global measurements of creativity, they may successfully measure specific aspects of creative capacity.156 These two types of instruments (i.e., intelligence and "creativity" tests) together with the personality measures, provide a broad spectrum of tests which, in combination, could provide initial bases for the new perspective on "creativity."

\section{The Creative Process}

Following immediately in the path of the works by Wallas, Poincaré, Patrick, Dewey and others in the first half of the twentieth century, Brewster Ghiselin's The Creative Process 157 appeared in 1952 , bringing to public attention the anecdotal writings of many of the eminently creative geniuses of the last two centuries on the subject of their own personal processes of creative thinking and creative production. Ghiselin proposed a generalized theory of the creative process following closely the outline of four stages suggested by Wallas and Poincaré before him. Although the stages were not necessarily illustrated or illuminated by each of the writers included in Ghiselin's volume, rich source material was provided by his work.

Following the creative experiences and processes described by Einstein, Coleridge, Poincaré and others in Ghiselin's collection, Mednick formulated a quite highly articulated theory of the creative process which he defined in a somewhat summary fashion as 
...the forming of associative elements into new combinations which either meet specific requirements or are in some way useful. The more mutually remote the elements of the new combination, the more creative the process or the solution. 158

He suggested three methods whereby such associations could be evoked: 1) serendipity in which the associative elements are "evoked contiguously by the contiguous environmental appearance...of stimuli which elicit these elements;"159 2) similarity in which the associative elements are evoked contiguously as a result of their similarity or the similarity of the stimuli eliciting them, and 3) mediation, in which elements shared in common by the key associative elements may mediate their assocation. 160

In articulating this associative process, Mednick was able to indicate, with clear implications, the place of "preparation" in the creative process: to wit, the accumulation of the requisite ideas or elements to be thus "associated." His description also accounted almost graphically for the incidence of multiple, though not necessarily "instantaneous," associations in both fluent and flexible manners without the stereotopic response pattern characteristic of the less creative individual. Further, Mednick's careful articulation of the associative process attained a broader psychological dimension with his suggestion of the cognitive or personality styles ("visualizer" and "verbalizer") revealed by the manner in which associative processes are elicited, which may also, as he indicated, "be partly responsible for differential aptitude for creative work in differing fields." 161

Although the "association of ideas" in creative thinking had been formulated variously by previous authors, and constitutes only 
one portion of the entire process of conceiving, formulating and producing a creative work, Mednick's articulation of the process brought practical demonstration and technical handling to the concepts involved. His Remote Association Test (RAT) operationalized his thesis in a form which could promote further research 162 and contribute to the development of modern conceptualization of the processes involved in creative thinking.

It should be noted that such an analytical advance in association theory was proposed by Guilford in 1959 and graphically systematized in his Structure of the Intellect model in 1965.163 while Guilford's measures of divergent thinking, derived from his work with the Aptitudes Project at the University of Southern California, provided test tasks for many of the 120 intelligence factors in the Structure of the Intellect model, 164 the specificity of the defined abilities and tasks guided his conceptualizations and his methodology along factorial lines. As a result, Guilford's work was directed quite specifically toward a mechanistic concept of steps in problem-solving as the basic prototype for creative thinking of all sorts.165 Guilford's problem-solving model 166 involved the essential elements of Wallas' four-stage creative process, which was researched and generally confirmed by Patrick between 1935 and 1955.167 Simply rendered, Guilford's model of the process of problem-solving can be seen to parallel the Wallas/Patrick four-stage model of creative thinking168 closely, particularly considering the double content of "preparation" for Wallas/Patrick which included both the gathering of information and conscious cogitation aiming at solution or breakthrough. 
Wallas/Patrick

1. Preparation

(and cogitation)

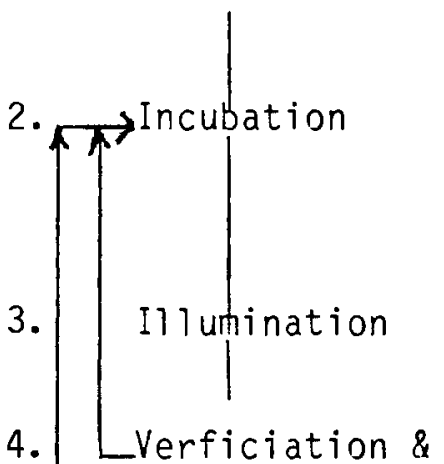

El aboration
Guilford

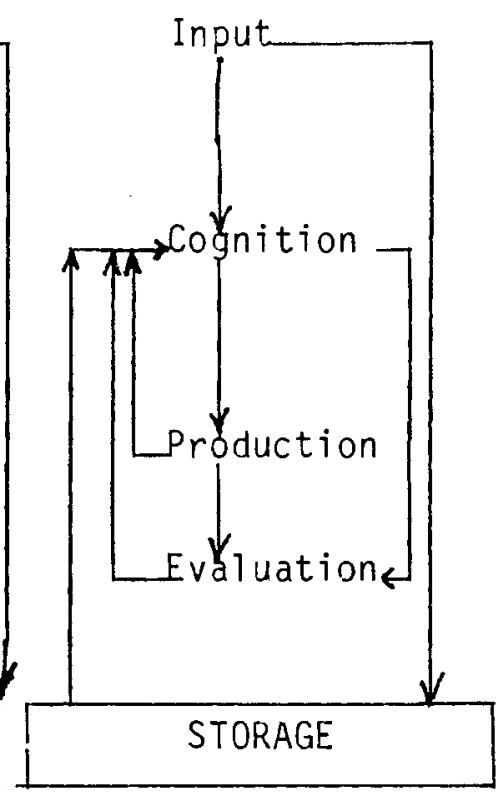

Comment

:Data gathered

:Problem sensed and structured (or new information obtained)

:Answer(s) generated

:Answer(s) tested

Figure 1. Stages in Wallas/Patrick's creative process model and Guilford's problem-solving model. 169

Guilford contributed a systematic description of the feedback loops between steps 2,3 , and 4 and suggested a loop between COGNITION and INPUT (omitted in the schematic above) with a "filter" operation inserted between the two to account for "recognition" of the cognition data after its original "cognition," perhaps an unnecessary complexifaction. What is cognized need not be transformed into new input to be re-cognized and evaluated. Patrick clearly suggested the occurrence of the basic feedback looping complexity in the Wallas stages as demonstrated by the artists' and scientists' processes she studied, which observation led her to assert that the stages were not adhered to in the formally sequential manner implied originally by Wallas. 170 Guilford's diagram also schematically represented the field of stored 
information (and experience) which underlies the thinking and productive processes, and with the graphic representation of this field gave perhaps more content to the fundamental concept of preparation (as basic information and experience gathering and storing) for problemsolving and creative processes than previous, disparate references to it such as Mednick's, Wallas' and Patrick's, and even Dewey's models and theories had done.

Guilford's paradigm, however, probably emphasized reasoning and tightly connected logical processes unduly in his schematization of the problem-solving process if he wished to represent the "creative" process, in general. Several essential features of the creative processes of innovations were excluded in the highly rationalistic formulation he propounded. For example, the common experience of becoming conscious of answers or solutions "suddenly bursting out of no where," as if by magic, and the experience of periods of rest or complete distraction as a time-lapse often intervening between hard work on the problem area followed by the sudden "illuminating" idea or solution seem to be precluded by implication from the logical "input""cognition" cycle. These experiences are more clearly recognized and implicitly included in Wallas' and Patrick's four-stage concept and are more easily accommodated by Mednick's process of the remote association of ideas with the methods he identified as operative in its activation. The cognitive framework and methodology used by Guilford predisposed his work to a heavier reliance on logical and systematic descriptions of operations than might be appropriate in representing the "creative process" distinctively. Guilford's allow- 
ance for either convergent or divergent processes as operative in the "production" stage does not entirely solve the basically mechanistic, "problem-solving" tenor of his model.

Wallas' four-stage concept was brought into modern perspective in 1955 by Patrick's What Is Creative Thinking? 171 in which the author analyzed in detail the stages which she had earlier researched and found to be accurate descriptions of procedures followed by both professional artists and scientists, excepting Wallas' implied strict sequential format.172 In what Is Creative Thinking?, the stages of 1 ) preparation, 2) incubation, 3) illumination, and 4) verification or revision are described with considerable content references to both artistic and scientific work in demonstration of one of Patrick's basic premises -- that the creative process is basically the same in both areas of work. Containing as it does voluminous references to the work of other psychologists and theoreticians, Patrick's text appears to be a psychologist's textual version of Rosamond Harding's An Anatomy of Inspiration, the Third Edition of which appeared in 1948, 173 and provides rich insights into the stages experienced by creative individuals as seen through the eyes of a psychologist. With Patrick's work, then, the creative process as a variable sequence of stages was brought into modern focus as a both active and passive process, capacities in each stage of which underlie summative creativity in any field. The Wallas/Patrick four-stage model of the creative process, with reinforcements from the similarly-based models by Poincaré and Ghiselin174 and Dewey, 175 appears to be the model most representative of the creative process experienced in the work of profes- 
sional artists and scientists. As such, the Wallas/Patrick model is of central importance as a reference point for modern psychological and educational research into creativity.

A fourth theory of the creative process, quite similar in tone to Guilford's, was proposed in 1962 by Torrance. Torrance introduced his conception of creativity in the form of a simple descriptive definition of creativity as "the process of forming hypotheses, testing hypotheses and communicating the results."176 Fifteen years later, Torrance expanded his definition and description with creativity's being seen

as the process of sensing problems or gaps in information, forming ideas or hypotheses, testing and modifying these hypotheses, and communicating the results.177

In this latter definition, Torrance actually stated a theory of a five-stage creative process, with the additional two initial stages being implied by the inclusion of "information" in which problems or gaps are sensed which leads to the formation of hypotheses. Simply diagramined, Torrance's vision of the creative process appears to be similar to both Guilford's and Wallas/Patrick's, with the exception of the final stage of "communication," which was not included in the others' theories or models. The inclusion of this fifth stage allowed Torrance's concept to advance the theory of the creative process in the practical dimension and to fit it more aptly for educative purposes. In fact, the recognition of the specific stage of the communication of creative production became, in Torrance's hands, a key area in which creative students could be guided in bringing their creations successfully and profitably to the attention of others so that their 
work might make positive contributions to their class or group rather than problems for themselves in the form of negative peer sanctions. 178

Wallas/Patrick

Torrance Guilford

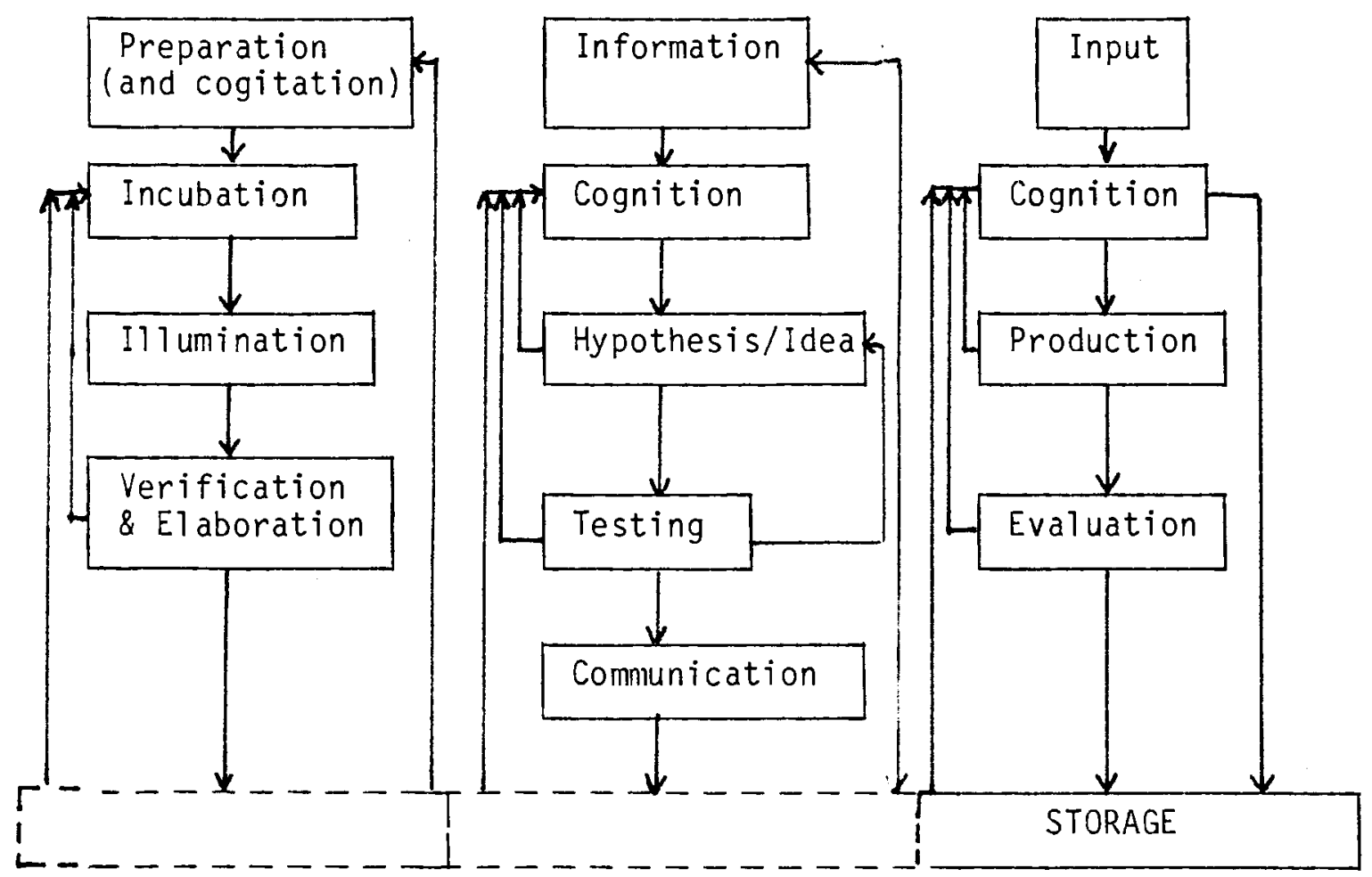

Figure 2. Stages in 'Nallas/Patrick's creative process model, Guilford's problem-solving model and Torrance's theory of the process of creating.

It is important to note that, however, well-suited to the educational setting, Torrance's view of the creative process shares more with the rational-mechanistic, basically problem-solving, model of Guilford than it does with the psycho-experimental view of the creative individual's processes of creation as conceived by Wallas and 
Patrick. In discussing his conception of the creative process in Rewarding Creative Behavior, 1965, Torrance not only qualifies the "hypothesis formulating" stages as one of "making guesses"179 (a more "natural" and comprehensible/acceptable description, he believes), but he describes the sub-processes (or looping processes) that naturally occur as "investigating, asking questions, manipulating things, making (more) guesses and the like."180 While somewhat similar to the basic problem-solving operations described by Guilford as "search for answers" or "seeking for new input information" with "ubiquitous" loops into evaluation, 181 Torrance's characterization of these processes and subprocesses are more distinctly suggestive of trial-anderror problem-solving operations than is even Guilford's model. In sum, while research expanded and insights accumulated concerning the usual steps or stages involved in the creative process, the post-Sputnik and the cybernetics and computer revolutions of the second half century have tended to predispose conceputalization of creativity toward problem-solving techniques and operations as in the processes described by Guilford and Torrance. Deriving from in-depth conceptions of how breakthrough ideas must occur and the processes experienced in the full deliverance of new creative works, Mednick, and Wallas and Patrick, propounded fruitful concepts of the distinctively "creative" process, the latter of which is based on a considerable store of evidence and descriptions from eminently creative individuals in Western civilization. 


\section{Additional Essentials in the Process of Creativity}

In addition to the widely researched personality characteristics of creative persons, some of the distinctive features of the styles of working shared in common by most of the manifestly creative individuals studied have been singled out by modern researchers bringing essential aspects of the creative processes into sharper focus. The features most importantiy noted converge around the special relationship or interaction which exists between the creative individual and his or her work. These features appear to be unique basic elements essential to the fruitful process of creative work which produces the breakthrough, the novel and useful, the "great" contribution.

First through her studies of both eminent artists and scientists, Roe observed one essential trait exhibited in common by all the artists and scientists: the "driven" personality, 182 a "driving absorption in their work."183 In Henle's words, this characteristic "absorption" is "immersion," 184 which she associated with the condition Newton described as "always thinking about it."185 May describes the absorption as "intense" and as responsible for the "encounter"186 which underlies, in his estimation, all genuine creative activity.

Second, in her studies of eminent scientists, Roe also observed that the scientists shared in common "the rarity of any indication of a drive for achievement."187 This latter feature seems to be directly related to the characteristic of involvement in creative adventure in which the ego is suspended or in descent in importance before the objective of the successful completion or "delivery" of the creative 
work, as implied by Pepinsky's research, 188 and the theories of May, 189 Kris, 190 and others. This feature of ego-lessness characteristic of the absorption or intense involvement in creative work is further described by Henle as a state of selflessness in which ...the ego lends itself to the work rather than dominating the task.... The main vectors of genuine thought often do not refer to the I with its personal interests; rather they represent the structural requirements of the given situation. 191

Norbert Weiner, creator of cybernetics, explained simply: "My ideas are my masters." 192 The involvement is further characterized by Henle as "detached devotion." 193

Patrick sheds a wider spectrum of light on this "absorption" through her analyses which identify an apparent "emotional" involvement 194 in the often difficult, up-and-down process of bringing a creative and wholly new work to complete form. The emotional involvement is but a testament to the depth of the typical immersion of the creative individual in the creative process. The "total personality" creates, according to Barron 195

The "intrinsic" nature of motivations and goals in genuinely "creative" activities is a fourth element in the creative process, as brought out by Crutchfield. In his analysis of the selfless, passionate, and total involvement in the process of creation, Crutchfield identified the source of both motivation and goals in "genuine" creative endeavor as intrinsic to the creative individual and the creative work rather than extrinsic:

...task-involvement in the creative act is not the same as the person's seeking to achieve 'creativity' per se as his goal. The latter is merely a form of ego-need in which the person strives to create in order to fulfill a certain self-conception--or a conception by others--that he is a 
'creative person.' Such deliberate strivings to be 'creative' are not likely to be conducive to genuine creativity. 196

One serious implication of this analysis is the casting of doubt on the validity of using external pressures of expectation or "direction" to stimulate creativity. As May explains, when creativity is "in the service of something...else, "197 the intense "encounter" or "absorption" may be lacking, and "this is the central feature of many kinds of artistic exhibitionism--what Rank calls the artiste manque. " 198

Given the above considerations of absorption, intense involvement, and the necessity of intrinsic motivation and goals, it would seem that freedom to follow one's own line of thinking, one's own processes to the ends they entail, is a prerequisite for authentic creativity; and this freedom to follow one's own thinking would seem to imply the precedence of the natural interests of the creative individual, as suggested by the extensive discussions of educators and psychologists, including Gowan and Demos, 199 Bruner, 200 Patrick,201 and Torrance. 202

Furthermore, the high degree of individuality and independence involved in the creative process, including the need to "let the mind wander," 203 combine to suggest hesitations about expectations for creativity in group contexts where group planning and group processes have the objective of achieving extrinsic goals of producing cooperative solutions and/or products. In fact, while there have been significant studies of group procedures, such as brainstorming, suggesting positive results, 204 deeper analyses of both the processes and the products involved in such procedures have led to negative assess- 
ments. 205 It is interesting to note that, while Parnes advocates the use of group brain-storming techniques to stimulate creative problemsolving, he notes, "By far the greatest percentage of time is spent in individual ideation and judgement."206 In their study, "Creativity and Personality," Cattell and Butcher point out the predominance of "introversion observed particularly among physical scientists" in juxtaposition to scientific research conditions today which

is increasingly a matter of team work, and the leader, or innovator, or inventor may appear to be highly dependent on effective cooperation and even on conventional social skills. But even in these conditions and in the field of technology and applied research, it has been frequently pointed out... that the individual, fertile originator remains the crucial factor in scientific progress; and this applies even more strongly in theoretical fields, perhaps especially in mathematics. 207

Cattell and Butcher go on to quote Van Zeist and Kerr's findings that scientific and technical personnel share a "disbelief in egalitarian 'committee-like' practices in research groups and a need for withdrawal and cogitation."208 Even more doubtful about the effectiveness of group-oriented procedures for stimulating creativity, Getzels and Jackson note that Mackinnon's close research observations "show that the group process does not yield proportionately more ideas, more unique ideas, or ideas of higher quality."209 They quote Mackinnon as concluding: "In fact, it appears that the group process inhibits creative thinking. " 210

The observations concerning creative individuals' responses to group-thinking processes would appear to lend credence to the suggestion that individual, personal interests and processes are fundamental 
to authentic creativity. In addition, the element of the considerable, even strenuous mental and emotional application typically involved in creative processes further supports the hypothesis that personal interests are at the base of creativity. This element of diligent application, which is often exhibited to the point of "dogged persistence," 211 is implied in the several stages outlined in all of the significant models of the creative process described previously. The initial "preparation (and cogitation)" ("input" or "information gathering") stage of this process requires that keen attention be applied in order for data to be accumulated and cogitated in their full complexity. Patrick described the preparation and cogitation stage repeatedly as "long and hard work, "212 often defeatingly so. 213 As Dewey maintained, inventions, solutions, discoveries rarely occur "except to a mind that has previously steeped itself consciously in material related to its question," (emphasis added)214 and Helinholtz's account of his creative process pointed out the concentrated effort involved in the cogitation that is a part of the preparation phase of creative work:

It is always requisite (for a discovery to emerge) that I should have turned my problem over on all sides, hither and thither, to the point where I could see all its terms and complexities in my head and could run through them without writing. To bring matters to this point is usually impossible without long preparatory 1 abor. 215

The diligent, absorbed work of "preparation-and-cogitation" ("input" or "information"), is actually, as implied by Bruner, akin to "practice, practice, practice," 216 for which continuous self-application is required. 
This level of concentrated work is needed not only in the initial preparation-cogitation stage (or the input, information stage followed by cognition) but, after the breakthrough or solution is achieved, in the final stage of "verification" ("testing," "evaluation," or "revision"). According to Patrick, "The final stage of revision or verification... is typically unpleasant and involves prolonged hard work."217 Further, Patrick notes: "Many persons become so discouraged in this final stage that they either abandon the whole project or else produce a second rate product." 218

Considering the effort that must be expended in absorption with the genuinely creative work, it would seem that, especially for the youthful, potentially creative individual, sufficient personal involvement would most naturally derive from personal curiosity, intrigue and interest; thus, the freedom required for creative activity would imply an allowance for even the young creator to follow personal bents and fascinations. 219

\section{Inspiration Through Modern Eyes}

In the treatments of creativity through the 25 centuries preceding the present, illumination or inspiration in the process of creativity was generally accepted as evidence of special, even divine, giftedness but it was otherwise little analyzed. With the works of Poincaré, Wallas and others early in the present century and with the popularization of the concepts involved in the creative process by Ghiselin's work in 1945, the place and character of inspiration in the creative experience began to be demarked and described in some detail. A full accounting has not as yet, however, been delivered. 
As represented in the modern Wallas/Patrick creativity model (Fig. 2), the central creative stage of "inspiration" or "illumination" is generally directly preceded by a period or phase of "incubation" in which the creator takes a rest froin the absorbing work in which he or she has been engaged. This latter stage is described and psychologically analyzed by Patrick:

After continuous work on a problem many inhibitions and interferences are set up. Relaxation allows these to die out, and permits a fresh approach to be made. When an inspiration comes in the midst of conversation or during other unrelated work, it is probable that some unnoticed stimulus has provoked a return to the original problem, which is solved inmediately because of the absence of the old conflicts and confusions. 220 Here, Patrick seems to be drawing implicitly on "association" to account for the spontaneous return to the previous subject of creative absorption and to be relying on some assumed giveness of "solution" or breakthrough which is immediately seen when the system is refreshed and confusions have faded away. Although Patrick's explanation of the spontaneous shift of attention seems apt, the assumption of the absence of disturbing elements and the consequent immediacy of insight does not seem sufficient; however, the suggestion of an interim connecting condition allows for the promise of deeper conceptual penetration into the creative process than previous views seem to offer.

In some of the nineteenth and early twentieth century discussions by creative individuals, a subtle progression of linkages between unconcerted "incubation" and sudden "inspiration" was variously implied--for example, Poincare suggested that "delicate intuitions" at the subliminal level are operative in "incubation" in his 
experience and led directly to the ultimate "illumination." His description of these intuitions is highiy suggestive:

The subliminal self is in no way inferior to the conscious self; it is not purely automatic; it is capable of discernment; it has tact, delicacy; it knows how to choose, to divine.... It knows better how to divine than the conscious self, since it succeeds where that has failed. 221

Poincaré described in more detail this "choosing" or "divining":

...the word (to choose) is perhaps not wholly exact. It makes one think of a purchaser before whom are displayed a large number of samples, and who examines them, one after the other, to make a choice. Here the samples would be so numerous that a whole lifetime would not suffice to examine them. This is not the actual state of things. The sterile combinations do not even present themselves to the mind of the inventor. Never in the field of his consciousness do combinations appear that are not really useful, except some he rejects but which have to some extent the characteristics of useful combinations. All goes on as if the inventor were an examiner for the second degree who would only have to question the candidates who had passed a previous examination. 222

As promising as this description is, Poincare did not attempt to account, in any systematic way, for the existence of the combinations among which intuition chooses; they appear to be simply assumed "givens." In a way foreshadowing Patrick's analysis, Poincaré seems to have assumed somehow that breakthrough solutions exist prior to their conscious recognition, which view has been implied throughout the long history of philosophical and critical analysis of creativity. His vision included, however, the operation of subliminal "delicate intuition" which presumably would link consciousness with the preconscious state of things (or events) in the "incubation" stage. Apparently, in the preconscious "incubation" stage, data is interconnected to different degrees of completeness, as it were; and intui- 
tion, somehow tuned to "sufficient completeness for solution," divines those "sufficient" combinations of data and therewith experiences "illumination."

Poincare's creative "subliminal self," of which he was obviously aware operating within himself, seems to have been advanced little toward the clarification of its implied operation as a subtle level of cognition or consciousness in "incubation" and "illumination" by modern psychological work in the field of creativity until Arieti's work, Creativity: The Magic Synthesis, in 1976. In this text, Arieti introduced a new concept of a "preconscious to subtiy-conscious" process which he termed "amorphous cognition." 223 This cognition has as its object the "endocept" which is a "primitive organization of past experiences, perceptions, memory traces, and images of things and movements."224 According to Arieti, the endocept is not "easily recognizable"225 but can be "felt" by some "as an atmosphere, an intuition, a 'global' experience that cannot be divided into parts...."226 Arieti postulated that "intuitional knowledge," which has often been linked to creativity, may be "endoceptual knowledge."227 Further, as "a large part of our conceptual life tends to fuse with an endoceptual counterpart, or to transmute into endoceptual forms...," 228 Arieti went on to posit that this conceptualendoceptual fusing or transmuting is a part of the "cognitive activity that eventually unfolds into the creative process."229

Arieti's conception of amorphous, endoceptual cognition seems to account more systematically than previous theories for both intuitive experiences in the creative process and the apparent prior existence 
or "given-ness" of the breakthrough ideas or solutions suddenly cognized in "illumination." In addition, Arieti offered a synoptic view of the creative individual's shifting of levels of cognition, which occurs in any of the several stages of the creative processes implied by Poincaré and others:

(the creative person) has seen (or "felt") a defect, or incompleteness, in the usual order of concepts, or has some other motive for dissatisfaction with it. Thus he brings part of his mental activity back to the stage of amorphous cognition, to that great melting pot when suspense and indeterminacy reign, where simultaneity fuses with sequential time and unsuspected transmutations occur. 230

Arieti's concept of amorphous cognition appears, most essential$7 y$, descriptive of the subtly-conscious or subliminal processes in "incubation" which can be further described as comprising "an indeterminate activity in search of a form, a groping for some definite structure."231 This description appears to fit we11, for example, with the characteristic experience of incubation in which the creative individual is somehow subconsciously preoccupied while he or she is about other activities. Arieti indicated that from "incubation" amorphous cognition itself leads directly to "illumination" (though he suggested that this is only one of many possible linkages): "When a suitable form is found, this activity is transformed into a creative work, at a more or less advanced stage of production" 232

With Arieti, then, we find a very modern psychological description of "incubation" and "inspiration." In both of these stages of the creative process, the sources of the content and the conscious operations themselves are within the individual as stored primitive or unrefined trace patterns of experiences of all kinds, together with 
natural neurophysiological processes. "Inspiration" appears to be on the threshold of becoming recognized as a potentially conscious, albeit subtly-conscious, process.

\section{Genius in the Age of Testing}

After the mid-point in the twentieth century, the question of "genius" did not preoccupy a significant number of researchers. According to Gowan and Demos in 1964, "...the word genius has gone out of fashion...."233 Further, they suggest,

...this is a natural and a hopeful development in a new science for it means we are beginning to disregard the spectacular and root our theory in the more useful study of larger groups.

The "larger groups" are identified and made available for research, today, by intelligence tests.

Although intelligence testing may have had the potential of obviating undue emphasis on the exceptionally or spectacularly talented or intellectually-gifted student as demonstrated by performance and obvious superiority of gifts, it may have done so in counterproductive ways. First, with the IO metric available, and following the studies in the early part of the century, the category "genius" did not vanish from use altogether but was rather installed as the generic term, along with "gifted," for individuals with high IQ's (over 150 on the Stanford-Binet scale) with a considerable narrowing of the term's meaning. As Thurstone noted in 1952,

...the Quiz kids are often referred to as geniuses. They would undoubtedly score high in memory functions, including incidental memory and rote memory. But it is doubtful whether they are also fluent in producing original ideas. 235 
Genius and creativity were technically and decisively separated when studies by Getzels and Jackson 236 and Torrance 237 established that the IQ level of 120 was the threshold beyond which intelligence and creativity appear to be entirely independent. The implications of this were spelled out by Torrance:

...identifying as gifted those students who score in the upper 20 percent of an intelligence test [about IQ 120 for Torrance] is to disregard 70 percent of the most creative, as similarly identified by a creativity test. 238

Second, the accessibility to teachers and educators in general of IQ scores magnified the importance of the narrow range of student capabilities measured by the intelligence tests and simultaneously diminished the importance of creative abilities. The results may be decided inequities in educational opportunities, 239 an inequality perhaps more generalized and extreme than the one the IQ metric was purported to be able to correct.

Genius has, since its origin as a concept, been identified with superlative human capacities, and particularly superlative creativity in the arts and sciences. Further, the modern consensus appears to be that "the abilities involved in being creative are universal, i.e., everybody possesses these abilities to some degree...."240 For these reasons it would seem exceptional that the current definition of genius should so clearly omit creativity. The exclusion from the classification of "genius" of those without superior giftedness in the highly circumscribed area of "intelligence" as assessed by modern intelligence or IQ tests, however, appears to be a result of circumstances involved in testing and measurement in this modern age. 
In the field of testing, which has won much confidence in the twentieth century, the testing of intelligence has proved itself to be much more dependable and useful than the testing of creativity. IQ tests measure abilities which can be definitively assessed by single established-right-answer methods, lending the credibility of validity and reliability to the instruments. Further, predictive power for IQ tests is also insured by the fact that the test instruments subject test-takers to school-related methods and measures in order to predict future success in a school or professional setting where tasks and objectives are based on the same fundamentally convergent-thinking and information-retrieval methods as the testing instrument itself.

In contrast to these advantages, the test instruments used to measure creativity which have been developed to date are comparatively weak in validity, reliability and predictive power. Not only are assessments still highly subjective and variable, but the capacities tested are in no way identical with ultimate manifest creativity. First, aspects of creativity are so divergent in character as to be almost impossible to anticipate or adequately judge. Even when creative individuals are in the ultimate position of performing creative work, "...society has often failed to recognize creative products until a generation or two after the persons who created them have lived."241 And further, as Fabun noted in 1970, "At the time of their introduction, most original ideas have met with ridicule, disapproval, opposition, or downright persecution." 242

Second, the processes involved in creativity appear to be too subtle to be, as yet, accessible to direct measurement or assessment, 
so only various somewhat artificial productions or superficial process-identifiers are available currently for use as test items which are, by definition, not indices of genuine creativity. It would appear, therefore, that tests to measure genuine creativity as yet fall short of the mark. 
CHAPTER IV

SUMMARY, CONCLUSIONS AND IMPLICATIONS

Summary

In order to obtain an in-depth vision of the "mysterious" human experience of intellectual breakthroughs and creativity, this study has examined the conceptions of creativity dominant in four highiy innovative periods in Western civilization: ancient Greece, the Italian Renaissance, the Age of Enlightenment in Europe and the twentieth century.

From the earliest literary records of Western civilization, there has been evidence of man's sensitivity to the mysterious experience of his own creativity. Nearly 3000 years ago, the extraordinary Homer repeatedly attributed his inspirations in the creation of both The Iliad and The Odyssey to the gods and muses. The earliest Greek philosophers represented their treatises as being nearly direct dictations from spiritual sources. By the time of $\mathrm{Plato}$, the assumption that creative motivation and direction issued immediately from suprarational sources had been a long-standing tradition as well as a part of the very fabric of philosophical, poetic and dramatic form. Plato recognized the evocative power of many such inspired works but, as sensitive as he was to the gifted and the gifts, he could not accept 
the inexplicable, hence non-rational, offerings of inspired verse and drama either as "truth's" or as experiences appropriate for personal development and good citizenship. For Plato, in fact, this very combination of emotional power and non-rationality constituted the danger for the public of the "free" creative works of men. For the sake of stability and the strength of the republic, Plato had to exclude from the state all gifted producers of inspired non-rational experiences. Rule and moderation, not excesses of pleasure and emotion, were proper goals for the ideal citizenry of the republic. In spite of Plato's harsh injunction against inspired works, however, creative philosophical and other literary works continued to be produced in ancient Greece, beyond the precincts of Plato's dreamed of Republic or State; and the creative individuals continued to attribute the sudden and surprising influxes of insight and inspiration in their conscious experiences to the obvious source--not, themselves, but some external power above and beyond them in knowledge and potency.

By the fifteenth century, events had combined to elicit unrivalled creative energy, production and accomplishment from the supremely gifted in Italy's city-states. $0 i 1$ and fresco painting, sculpture, poetry, philosophy, criticism and drama all flourished in the intense reflection of light and life emitted from the discovered remnants of Rome's great past. The Italian Renaissance cast its spell of creativity over centuries to come. At the center of the emanations was a Christianized Neoplatonism in which man was reconceived as endowed from birth with natural creative powers which only needed to be 
unfolded through active creative, productive endeavor. The site of mysterious creative 117 uminations or inspirations was, for creative individuals in the Renaissance, localized "within" the creative individual, and those most richly endowned with "genius" were esteemed as no less than God-like or divine.

As the Renaissance cities of Italy continued for two centuries to build and flourish in the currents of rebirth, creativity was installed at the zenith of human experience and promise. With the source of creative inspiration and insight having been identified as, in varying degrees, within every man's own nature (ultimately, it was thought, elevating him to become the very creator of himself), man's gifts, no matter how exceptional or extreme, were conceived as selftranscending and full of excellence. Through the Neoplatonism of the Renaissance, the fact that inspiration remained wholly inexplicable in anything but non-rational, spiritual terms caused no hesitations of reason and the fact that "genius" was observed to be somewhat touched with the unreasonable, with madness, itself caused no hesitation in analysis or act. The splendor of creative power ruled the times and demonstrated the heights to which creative attainment could climb in the encouraging climate. Creativity thus became the summit of human experience and supremely creative individuals the idols of the age.

The eighteenth century for Europe was a century of profound awakening to new visions of the powers of reason and artistic expression, as is suggested by its designation as "the Age of Enrightenment." France, the leading country of Europe's Enlightenment, was deeply embued with Cartesian rationalism from the 1600 s and the 
attendant great drama, poetry, and critical writings of French $\mathrm{Classicism}$ from that century. Led by Boileau, Classicist criticism, with its reliance on logical method, rule, deduction and basic principles, dominated the critical works of both France and England during most of the years of the Enlightenment.

The fundamental principle ruling the arts for sixteenth century Classicists was "imitation," and results of imitative arts during the Enlightenment were satisfying enough to obscure, to an extent, the contradiction between "pure imitation," as the perfect method of brilliant artistic accomplishment, and the exceptional effective results possible through often thoroughly "inexplicable" means or methods--the ever-present non-rational element in creative fine arts. Boileau led the later $\mathrm{Cl}$ assicists to recognize this element when he asserted, quite like Plato, that the poet not under divine influences at birth could never produce works of the highest order. The clarity of French Enlightenment ratonalism brought the phrase "je ne sais quoi" ("I don't know what") into service as the suggestive, if not wholly revelatory, description both of the quality of the brilliant work and also of the element of greatness in the "born" genius.

Following Boileau, the French rationalist critics, Bouhours and Dubos, penetrated further into the experience of artists' nonrational processes and introduced the concepts of "delicatesse" (sensitivity) and "indistinctness" as key elements in the artists' creative processes and in the appreciators' experiences. Alongside reason and rule, "feeling" and "being moved" were acknowledged as motive forces in creativity and aesthetic experience. 
The surest voice in English Enlightenment aesthetics was that of the Neoplatonist, Shaftesbury, who raised creative genius even above the previous heights of divine, inborn gifts of artistic creativity. Shaftesbury saw in artistic creation a replication of nature's own essential foment of productive changes and recognized artistic creativeness underlying intuitional understanding as the only technique for truly comprehending nature in its essence. This, for Shaftesbury, was the quality of genius. The basis of "knowledge" here shifted from logic and the deductive rules of reason to the suprarational faculty, intuition. Shaftesbury further articulated the formative role of imagination in creative enterprise, bringing "inspiration" into nearly conscious, voluntary control by the creative individual.

The Enlightenment's high conception of the inexplicable, nonrational quality of superlative creative productions was summed up by Immanuel Kant's final suggestion that the genius "does not himself know how the 'ideas' for (his creation) have entered his head..., "243 and that it is in the nature and power of this non-rational element of genius to give "the rule to art."244 Further, Kant gave one of the first psychological descriptions of the difference between creative genius and scientific giftedness asserting that the latter deserved the highest distinction because its work was rational and capable of being communicated to others (i.e. was "knowledge") while artistic creative processes and products could not be fully explicated or communicated (i.e. were not "known" or understood).

Although beginning on a strongly rationalistic footing, the Age of Enlightenment brought into play observational approaches to crea- 
tivity which revealed important psychological elements, such as imagination's role in inspiration and emotion's role in providing internal motivation and directon. Genius continued to be conceived as inborn, but its attributes were more clearly distinguished than previously, including acknowledgement of the inexplicable arrival of ideas and their frequently experienced quality of being laws unto themselves. Further, while genius continued to be directly identified with artistic creativity, scientific giftedness was distinguished as rational and communicable, and this distinction implied an unanalyzed dissimilarity of productive process. The laurel for heights of human achievement was divided in this Age: early, the Neoplatonist Shaftesbury followed the Renaissance's lead and enthroned creative genius as the epitome of human experience; later, the idealist Kant enthroned scientific endeavor as the zenith of human enterprise.

The times proceeded with increasing dedication of energies along the lines of scientific advancement and high valuation of intellectual rationality over all, ultimately to usher in the first half of the twentieth century, deeply embued with observational predisposition, objectivity orientation and research mindedness. The twentieth century was also given a special forward thrust for creativity theory by the work of Galton in the mid-nineteenth century with its broad-based correlational studies and its close association of genius with both creativity and intellectual giftedness. The two directions proved significant for the new century's concepts of creativity and genius. Early in the twentieth century, statistical and experimental methodologies combined to produce intelligence tests. Due to the 
implied association of intellectual endownment (giftedness) and creativity (genius), exceptionally intellectually gifted students, as identified by intelligence (IQ) tests, were promptly labelled "geniuses," as in the early works of Terman and his associates. In time, however, "genius" lost nearly all articulated or assumed reference to creativity, as intelligence tests were the identifiers of high IQ and genius, but those who scored high in IQ often proved to be neither obviously innovative nor outstandingly creative.

As the century got underway, the early experimental work on intelligence tests, as well as Terman's massive study of young geniuses, involved observation of various traits of personality, behavior, background, etc., which data formed the basis for the specialized study of personalities of the exceptionally endowed. These studies multiplied in the second half of the twentieth century. In the midst of the surging interest in exceptional intelligence and genius early in the twentieth century, attention was drawn to the "mysterious" process by which scientists and artists came to their breakthroughs by the works of Poincaré and Wallas, both of whom suggested a similar four-stage process to be operative. The four-stage processes included two reassuringly rational, explainable, stages (1-preparation and 4-verification) and two more mysterious, nonrational stages (2-incubation and 3-illumination). The stages of creative work were soon recognized as generally the same in all creative fields from science and mathematics to art and literature. Through these early systematic treatments, the entire creative process was somewhat demystified. 
Creativity theory in the second half of the twentieth century was given an unprecedented upsurge in attention as a result of the 1950 Presidential Address to the American Psychological Association by J.P. Guilford when he assailed his fellow-psychologists with his vision of the "appalling neglect" of the subject of creativity in the field of psychology. Studies sprang up on all sides, with particular concentrations in the areas of personality traits of creative individuals, creativity tests and the creative process. No little extra impetus was given to the interest in creativity when Sputnik was 1 aunched in 1957, alerting the entire American nation to the need for "more creativity," particularly in the sciences and in technological fields.

In-depth studies of the creative personality began to identify the anomolous personality and behavior patterns of creative individuals and to promote the first serious and broad-spectrum studies of these divergencies, their effects, and (surprisingly) their possible necessity. The special difficulties these personality proclivities (including non-conformity) created for the creative individuals from childhood in school settings among peers with more normal traits and behavior patterns became a serious focus of attention among researchers, as did the possible personal, societal and national costs associated with the thwarting of creativity.

Further, however "out of tune" the divergent behaviors and processes of creative individuals were with general group processes, and however difficult creative persons were, as a consequence, to handle in group situations such as the regular American classroom, it 
became apparent that the singular patterns of creative persons were partially responsible for the achievement of innovation and the successful production of the new creative work. As a result, psychologists and educators began to conceive education's roles with respect to creative students as more supportive, facilitative and constructively guidance-oriented than previous conceptions had envisioned.

A significant portion of Guilford's landmark Address dealt with the inadequacy of the widely-used intelligence tests to measure specific or general qualities of creativity. His analysis included suggestions for tasks which might be employed to measure the capacities or aptitudes related to creativity according to his detailed Structure of Intellect model. Within a decade, Torrance and his colleagues at the University of Minnesota had produced their battery of tests known as the Minnesota Test for Creativity based centrally on the capacity of divergent-thinking as defined by Guilford. The Minnesota Test was soon broadened and reproduced as the Torrance Tests of Creative Thinking. Other creativity tests were developed during these years, including tests similar to Torrance's (The Wallace and Kogan Battery, the Getzels and Jackson Battery, and the Guilford divergent-thinking tests) and other types of tests (the Barron-Welsh Art Scale, Stein's Physiognomic Cue Test, and Mednick's Remote Association Test). Most of the creativity measures developed after the mid-century have been widely tested and generally fall somewhat short of strong reliability and predictive and discriminant validity. The Torrance, Wallach and Kogan, and Getzels and Jackson Batteries are the creativity tests most 
widely used and appear to provide only suggestive indications of creative capacity.

The creative process received in-depth attention after the midcentury, primarily through adaptations of Wallas' earlier four-stage model (preparation, incubation, illumination and verification) originally validated by Patrick. Guilford's similar four-stage model provided a more mechanistic interpretation of the stages identified by Guilford as input, cognition, production and evaluation; in Guilford's model, however, the storage of information and retrieval loops were given the clearly active description required to account for both problem-solving and creating. Torrance developed yet another variation, adding the significant fifth stage of "communication" to the general model.

The Wallas/Patrick model, with its two non-rational stages (2-incubation and 3-illumination) appears to articulate the experiential qualities of the basic stages of creativity more aptly than Guilford's or Torrance's more mechanistic paradigms. The appropriateness of the inclusion of the non-rational experiences in the Wallas/ Patrick process model is validated by the sensitive suggestions given in Poincaré's description of his processes, which are not unlike those of many other eminently creative individuals. Further validation is added by the most recent psychological analysis of the subtlest aspects of creativity (the arrival, through vague processes of incubation, at illumination) by Arieti.

The wide range of extensive analytical and theoretical work in recent years by educators and psychologists has further identified 
significant aspects of the creative personality and the creative process which shed increased light on creativity as a whole. The special absorption and drivenness of the creative personality at work, characterized by ego-less dedication toward intrisically interesting and important goals, provides a focus of attention for educators and psycholgists alike with significant ramifications for such considerations as the utility of group-thinking and brain-storming processes in promoting creativity and the need to allow students freedom to explore personal interests in the classroom setting and beyond.

Two additionally important considerations emerge from modern research which psychologists and educators must ponder concerning the identification of and education for creativity. First, early signs of even the greatest ultimate innovativeness, such as Charles Darwin's, are mysteriously absent, even to retrospective vision. Second, according to modern informed thought, the trait or combination of traits of creativity are normally distributed across the entire population, and therefore it has been asserted that "the abilities involved in being creative are universal." 245

Finally, in the recent few decades, "genius" has arrived at a rather restrictively delimited definition due to the prevalence and predictive power of intelligence tests as used in the psychological and educational settings. Genius is identified as an IQ of 150 or above on the Stanford-Binet scale or its equivalent on other tests scales. Creativity, which until recently was a significant, if not the only, factor in establishing an individual as a "genius," has all but dropped entirely out of view as related to genius, due especially 
to the fact that IQ test scores over 120 have repeatedly been demonstrated to be independent of creativity as measured (however uncertainly) by creativity tests and, of the most creative students in school, 70 percent have IQ's below 120. As IQ tests began to dominate the modern educational setting, their initial correction of undue emphasis on spectacular individual performance may have ultimately resulted in a new emphasis on Quiz Kid geniuses, with a resulting disregard of and under-service thereby to 70 percent of the most creative students in the schools.

\section{Conclusions and Implications}

From the study that has been completed, several conclusions can be drawn with implications for future research and educational applications.

Over the centuries, creativity and intelligence have been variously separated and combined, resulting in a continuing confusion between the two and inconsistency in their treatment. The use of the term "genius" demonstrates the issue. While previously the term had been reserved nearly exclusively to denote eminent creativity, at present "genius" is used in the fields of psychology and education as the generic descriptor for exceptionally high intelligence or IQ. At the same time, the suggested separation of creativity from intelligence in this revised use of "genius" is gainsaid by the explicit association of the two in the current conventional usage of the term to mean "exceptional intellectual and creative power." 246

Further, with intelligence tests holding unprecedented authority in assessment in the educational environment, achievement across the 
full range of subjects is construed to be directly related to intelligence; where IQ and achievement levels are at variance, the relative terms of "under-" and "over-achiever" have been used to "explain" the discrepancies. The possible contribution or effect of creativity in either case has been generally ignored. Ultimately, creativity has been implicitly subsumed under the dominant category of intelligence with even creative excellence itself being casually assumed to reflect high IQ or over-achievement.

In view of the confusions resulting from the nonsystematic separation and combination of creativity and intelligence, and the commonly implicit disregard of creativity altogether, it appears at this point to be vital to distinguish creativity definitively from intelligence. As intelligence is highly rewarded in the culture at this time, and creativity appears to be both exceptionally important and implicitly thwarted, the distinguishing features of each need to be brought to clear demonstration so that the promotion of each can be addressed incisively. The first step in distinguishing creativity from intelligence must be the development of a definitive concept of creativity based on its unique features and attributes.

Research trends to date suggest a broad and inclusive conceptualization of creativity as a multifaceted capacity involving the intelligence factors of divergent-thinking and crystallized and fluid intelligence, along with a wide range of personality factors. This concept of multifacetedness may ultimately be refined to a fruitful and definitive characterization of creativity, in general; however, viewed within these intellectual and psychological parameters, the 
specific and unique factors of creativity may actually be obscured. For example, crystallized intelligence factors appears to be fundamental to both intelligence and creativity, and fluidity is, in and of itself, often a subjective judgement and the factor may be characteristic of many mental operations in addition to those involved in creativity. As a result, these factors would appear to be more promising for "describing" creativity than for "discriminating" creativity from intelligence or other mental capacities. Similarly, psychological traits such as non-conformity and driven-ness of personality are characteristic of many persons other than the highly creative, so their use in developing a distinct profile for identification of creative personalities may be ultimately limited.

The heart of the issue of developing a discriminative definition of creativity seems to be in selecting the most promising point of departure and it would appear that focusing on the unique aspects of the "creative process" itself should reveal the most definitive features of creativity. The most useful model of the creative process to date appears to be the Wallas/Patrick four-stage model. Central in the process is the stage of illumination in which the unique experience of the creative "breakthrough," the "decidedly new and effective vision," is experienced. Although certainly there must be unique attributes to the creative sub-processes involved in the stages of preparation and verification which must be researched, the unique mental operations and experiences involved in creative incubation and illumination seem to be the sites at which the most unique features of creativity must be isolated, defined, and ultimately distinguished 
from other mental operations which it shares in common with general intelligence. Arieti's proposals of endoceptual processes with their suggested natural organizational structure and subtle connections appear to be promising preliminary steps. The work needs to be filled out and more completely ramified. Additionally, recent neurophysiological findings must be reviewed and brought into relation with the psychological and mental processes involved in creativity where relevant and if possible.

Once a finely discriminative definition of creativity has been achieved, a battery of tests must be developed and refined to assess creative capacity as distinct both from other mental capacities and from other patterns of psychological styles, as well. For example, it seems clear that while the capacities of gaining fluid and in-depth access to rich reservoirs of retrievable experience and of sustaining intense involvement, persistent self-application, independence of mind, and so forth are necessary intellectual and psychological attributes of the creative individual, they seem to function as the background or intellectual/psychological topography necessary for the manifestation of creativity rather than as creativity itself. A definitive test of creative capacity would have to assess precisely those traits which function in bringing about the conscious cognition of previously unknown or unrecognized links between the current unsatisfied or problematic situation and the new apt and satisfying resolution.

Until such a definitive and discriminative test has been devised, it would seem that the current multifaceted conception of 
creativity provides the best clues to the general characteristics of the capacity. Creativity, conceived in this way, would seem to be accessible to measurement by a combination of currently available creativity and intelligence tests together with personality measurements for the purpose of initial identification, albeit a tentative one, of potentially creative individuals. At the present, creativity tests are generally quite unpredictive and therefore are, by themselves, insufficient measures of real creative capacity; however, they may be more suggestive of creativity-specific capacities than either intelligence tests or psychological measurements alone and, as such, would be a key component in a combination-test program for creativity where such testing appears to be necessary.

Finally, serious consideration needs to be given to the recent suggestions of psychologists and educational researchers that creativity may well be a trait normally distributed in varying degrees across the entire population and that early signs of great creative powers may continue to be indiscernable. If stultified creativity entails the personal, social and national costs that have been hypothesized, the most important concern for educators of the present may be how to facilitate the growth and development of creativity of a11 students throughout their entire educational careers. 
1 Plato, "Ion," The Dialogues of Plato in Two Volumes, trans. B. Jowett (New York: Random House, 1937) I: 289.

2 Plato, "Ion," Dialogues I: 289.

3 Plato, "Laws IV," Dialogues II: 490.

4 Homer, The Iliad of Homer, trans. Richard Lattimore (Chicago: Univ. of Chicago, 1951) 59.

5 Homer, Iliad, 240.

6 Homer, Iliad, 240.

7 Homer, "The Odyssey," The Iliad of Homer and The Odyssey,

trans. Samuel Butler (Chicago: Benton-Brittanica, 1971) 227.

8 Homer, "Odyssey," 227.

9 Homer, "Odyssey," 227.

10 George F. McLean and Patrick J. Aspe11, Readings in Ancient Western Philosophy (New York: Appleton, 1970) 39.

11 McLean 40.

12 See Plato, "Meno," Dialogues I:379 and "Ion," Dialogues $I: 253-4$.

13 E. R. Dodds, The Greeks and the Irrational (Boston: Beacon Press, 1957) 82.

14 Plato, "Apology," Dialogues I:405.

15 Plato, "Phaedrus," Dialogues I:245.

16 Plato, "The Republic, Book III," Dialogues I:661.

17 Plato, "The Republic, Box X," Dialogues I:865.

18 plato, "Laws, Book III, Dialogues II 457. 
19 Paul Oskar Kristeller, "Renaissance Platonism," Facets of the Renaissance, ed. W. K. Ferguson (New York: Harper \& Row, 1959) 108. 20 Marsilio Ficino, "Platonic Theology," qtd. in Charles Trinkhaus, In Our Image \& Likeness, 2 vols. (London: Constable, 1970) II $: 486$.

21 Erwin Panofsky, "The Renaissance: Artist, Scientist, Genius: Notes on the 'Renaissance Dammerung,'" The Renaissance: Six Essays, W.K. Ferguson et al. (New York: Academy Lib., 1953) 129.

22 Trinkhaus I: 53.

23 Manetti, "Dignity and Excellence of Man," qtd. in Trinkhaus I: 247.

24 Pico della Mirandola, Oration on the Dignity of Man, trans. A. R. Caponigri (Chicago: Henry Regnery Co., 1956) 4.

25 Mirandola 3.

26 Mirandola 14.

27 Panofsky 172.

28 Giorgio Vasari, Lives of the Artists, trans. George Bull (Middlesex, England: Penguin Books, 1965) 360.

29 Vasari 284.

30 Vasari 342.

31 Henry Guerlac, "Where the Statue Stood: Divergent Loyalties to Newton in the Eighteenth Century," Aspects of the Eighteenth Century, ed. Earl R. Wasserman (Baitimore, Maryland: Johns Hopkins P, 1965) 324.

32 Ernst Cassirer, The Philosophy of the Enlightenment (Princeton, New Jersey: Princeton UP, 1951) 280. 
33 Cassirer 280.

34 Cassirer 285.

35 R. Willkower, "Imitation, Eclecticism, and Genius," Wasserman 157.

36 Cassirer 301.

37 Katharine Everett Gilbert and Helmut Kuhn, A History of Aesthetics: Revised and Enlarged (New York: Dover, 1972) 274-277.

38 Anthony Ashley Cooper, Third Earl of Shaftesbury, was the grandson of the noted Cromweillian politician and patron of John Locke, Anthony Ashley Cooper, First Earl of Shaftesbury.

39 Cassirer 313.

40 Cassirer 326.

41 Cassirer 317.

42 Cassirer 327.

43 Anthony Ashley Cooper, Third Earl of Shaftesbury, Characteristics of Men, Manners, Opinions, Times, ed. John M. Robertson (New York: Bobbs-Merri11, 1964) 36-37.

44 Immanuel Kant, The Critique of Judgement, First Part: Critique of Aesthetic Judgement, trans, J.C. Meredith (Chicago: Benton, 1971) 525.

45 Kant 526.

46 Kant 526.

47 Kant 526.

48 Francis Galton, Sir, Hereditary Genius: An Inquiry into Its Laws and Consequences (New York: Horizon P, 1952) 1. 
49 Frederick Adams Woods, "Historiometry as an Exact Science," Science, ns 33.850 (1911): 568-574.

50 Galton 43.

51 Jacob W. Getzels and PhilipW. Jackson, Creativity and Intelligence (New York: Wiley, 1962) 4.

52 Lewis M. Terman and Mileta H. Ogden, The Gifted Child Grows Up: Volume IV of Genetic Studies of Genius (Stanford, Calif.: Stanford UP, 1947) 18.

53 Terman and Ogden 26.

54 Terman and Ogden 32.

55 Terman and Ogden 26.

56 Terman and Ogden 1. See also: Catherine M. Cox, The Early Mental Traits of Three Hundred Geniuses: Volume II of Genetic Studies of Genius (Stanford, Calif.: Stanford UP, 1926) 15.

57 Terman and Ogden 20.

58 Terman and Ogden 19.

59 Lewis M. Terman, The Gifted Group at Mid-Life: Volume V of Genetic Studies of Genius (Stanford, Calif.: Stanford UP, 1948).

60 Herbert A. Carrol1, Genius in the Making (New York: McGraw, 1940) 38.

61 Carrol1 205.

62 Carroll 204.

63 carroll 207.

64 G. V. Dearborn, "A Study of Imagination," American Journal of Psychology 5.9 (1898) 183-190; qtd. in Stephen Harvey, "A New View of 
the Relationship between Creativity and Intelligence," Journal for the Education of the Gifted 5.4 (1982) 296.

65 Getzels and Jackson 4.

66 R.M. Simpson, "Creative Imagination," American Journal of

Psychology 33 (1922) 234-5; qtd. in Jacob W. Getzels and M.

Csikskentmihalyi, "From Problem Solving to Problem Finding,"

Perspectives in Creativity, eds. Irving Taylor and Jacob W. Getzels

(Chicago: Aldine Pub. Co., 1975) 94-95.

67 Getzels and Jackson 6.

68 For example, Laura M. Chasse11, "Test for Originality,"

Journal of Educational Psychology 7 (1916) 317-328; Simpson 243; and

Elizabeth Andres, "The Development of Imagination in the Pre-school

Child," U. of Iowa Studies in Character 3.4 (1930).

69 Henri Poincare, "Mathematical Creation," The Foundations of

Science, trans. George B. Halsted, 1915, 22-31; rpt. in Brewster

Ghisel in, The Creative Process: A Symposium, (Berkeley, Calif.: UC

Berkeley P, 1954) 27.

70 Poincare 27

71 G. Wallas, The Art of Thought (New York: Harcourt, 1926).

72 c. Patrick, "Creative Thought in Artists," Journal of

Psychology 4 (1937) 35-73.

73 John Dewey, Art as Experience (New York: Capricorn Books, 1934) 266.

74 Dewey 266.

75 A. Alpert, "The Solving of Problem Situations by Pre-school

Children," Teach. Coll. Contrib. Educ., Columbia U 323 (1928); qtd. in 
Catherine Patrick, What is Creative Thinking? (New York:

Philosophical Library, 1955) 36.

$76 \mathrm{~J}$. L. Lowes, The Road to Xanadu (New York: Houghton, 1930).

$77 \mathrm{~J}$. Rossman, The Psychology of the Inventor (Washington, D.C.: Inventors Pub. Co., 1931).

78 Irving A. Taylor, "A Retrospective View of Creativity Investigation," Taylor and Getzels 16.

79 Donald W. Mackinnon, "IPAR's Contribution to the Conceptualization and Study of Creativity," Taylor and Getzels 61.

80 Jacob W. Getzels and M. Csikskentmihalyi, "From Probiem Solving to Problem Finding," Taylor and Getzels 95.

81 J.P. Guilford, "Creativity' Address of the President of the American Psychological Assoc., "Penn. State College, September, 1950, The American Psychologist 5 (1950) 444-454; rpt. in J.P. Guilford, Intelligence, Creativity, and their Implications (San Diego: Knapp, 1968) 78-79.

82 J.P. Guilford, "Creativity: A Quarter Century of Progress," Taylor and Getzels 37.

83 L. L. Thurstone, "The Scientific Study of Inventive Talent" (1952); rpt. in S.J. Parnes and H.F. Harding, eds, A Source Book for Creative Thinking, (New York: Scribner's, 1982) 58.

$84 \mathrm{~F}$. Barron, "The Disposition toward Originality," Journal of Abnormal Psychology 51 (1955):478-85; rpt. in P.E. Vernon, ed., 
Creativity (Middlesex, Eng.: Penguin, 1970) 273-88. See also: Anne Roe, "A Psychologist Examines Sixty-Four Scientists," Scientific American 187 (1952): 21-5; rpt. in Vernon 43-51. See also: John Curtis Gowan and George D. Demos, The Education and Guidance of the Ablest (Springfield, 111.: Chas. C. Thomas, 1964). 85 R. B. Cattell, and H. J. Butcher, The Prediction of Achievement and Creativity (New York: Bobbs-Merri11, 1968) 227-8; rpt. as "Creativity and Personal ity" in Vernon 312-315. See also: Richard S. Crutchfield, "Conformity and Creative Thinking," Contemporary Approaches to Creative Thinking, eds. Harold E. Gruber, Glenn Terrel1 and Michael Wertineimer (New York: Atherton P, 1962) $120-140$

86 Carl R. Rogers, "Towards a Theory of Creativity," ETC: A Review of General Semantics 11.4 (1954); rpt. in Harold H. Anderson, ed., Creativity and Its Cultivation, (New York: Harper \& Bros., 1959) 73.

87 Barron 273. See also: Cattell and Butcher.

88 E. Paul Torrance, "Education and Creativity," Creativity: Progress and Potential, ed. Calvin w. Taylor (New York: MacGraw, 1964) 99 .

89 Torrance, "Education and Creativity" 101.

90 Richard S. Crutchfield, "Conformity and Creative Thinking," Contemporary Approaches to Creative Thinking, eds. Harold E. Gruber, Glenn Terrell and Michael Wertheimer (New York: Atherton P, 1962) $120-1$ 
91 F. Barron, Creativity and Personal Freedom (New York: D. Van Nostrand, 1968) 35. See also: Roe 43-51.

92 Ziegfield, Art for the Academically Talented Student in the Secondary School (Washington, D.C.: National Education Association, 1961); qtd. in E. Paul Torrance, Creativity in the Classroom (Washington, D.C.: National Education Association, 1977) 116.

93 Arnold Toynbee, "Has America Neglected Her Creative Minority?" Utah Alumnus (February 1962): 10; rpt. in C.W. Taylor, ed., Widening Horizons in Creativity (New York: Wiley, 1964) 4.

94 Calvin W. Taylor and R.L. Ellison, "Moving Toward Working Models of Creativity," Taylor and Getzels 194.

95 Getzels and Csikszentmihali 95.

96 Hans J. Eysenck, "The Roots of Creativity: Cognitive Ability or Personality Traits?," Roeper Review (May 1983): 12.

97 Getzels and Jackson 125.

98 John Curtis Gowan and George D. Demos, The Education and Guidance of the Ablest (Springfield, 111.: Chas. C. Thomas, 1964) 87. 99 Torrance, "Education and Creativity" 100. See also: Jerome Bruner, "Learning and Thinking," Harvard Education Review 29 (1959): 184-192; qtd. in Bernard T. Thacker and Edward S. Rosenbluh, "Creativity as a Reflection of Teacher-Pupil Relationships," Psychology 9.1 (1972): 25

100 Rogers 70.

101 J.P. Guilford, "Traits of Creativity," Creativity and Its Culivation, ed. Harold H. Anderson (New York: Harper \& Bros., 1959) 
102 T.A. Razik, "Psychometric Measures of Creativity,"

Explorations in Creativity, ed. R.L. Mooney and T.A. Razik (New York: Harper, 1967) 302.

103 Sarnoff A. Mednick, "The Associative Basis of the Creative Process," Psychology Review 69.3 (1962): 220.

104 Pauline N. Pepinsky, "A Study of Productive Nonconformity," The Gifted Child Quarterly (Winter 1960): 81-86.

105 E. Paul Torrance, "Current Research on the Nature of Creative Talent," Journal of Counseling Psychology 6(1959): 315; rpt. in Gowan and Demos 83.

106 Robert C. Wilson, "Developing Creativity in Children," Education (Sept. 1960): 22.

107 Rollo May, The Courage to Create (New York: Bantam, 1975) 42-43.

108 L. Hudson, Contrary Imaginations: A Psychological Study of the Young Student (New York: Schecken, 1966) 121: qtd; in George S. Welsh, Creativity and Intelligence: A Personality Approach (Chapel Hill, NC: U of NC P, 1975) 7.

109 Ann Roe, "A Psychologist Examines Sixty-Four Eminent

Scientists," Scientific American 187(1952): 21-5; rpt. in P.E. Vernon, ed., Creativity (Cambridge, Eng: Penguin, 1970) 50.

110 E. Paul Torrance, "Developing Creative Thinking through

School Experiences," rpt. in Parnes and Harding 33.

111 Torrance, "Developing" 32.

112 Toynbee 6 .

113 Mackinnon 60-89. 
114 Barron, Creativity and Freedom.

115 Getzels and Csikskentinihalyi 95.

116 Guilford, "'Creativity' Address" 80.

117 Guilford, "'Creativity,' Address" 84.

118 simpson 94-95.

119 Guilford, "'Creativity, ' Address" 90-96.

120 E. Paul Torrance, "Factors Affecting Creative Thinking in

Children: An Interim Report," Merrill-Palmer Quarterly (1961): 171180. See al 50: E. Paul Torrance, Rewarding Creative Behavior

(Englewood Cliffs, N.J.: Prentice, 1965) 32-38.

121 Torrance, "Education and Creativity" 83. See also: E. Paul Torrance, Torrance Tests of Creative Thinking: Norms Technical Manual (Englewood Cliffs, N.J.: Prentice, 1965) 36.

122 E. Paul Torrance, Rewarding Creative Behavior (Englewood Cliffs, N.J.: Prentice, 1965) 36.

123 Gowan and Demos 80.

124 Susan B. Crockenberg, "Creativity Tests: A Boon or Boondoggle for Education?", Review of Educational Research 42.1 (1972): 35 .

125 Crockenberg 39.

126 E. Paul Torrance, Creativity in the Classroom (Washington, D.C., National Education Association, 1977) 6.

127 Crockenberg 35-37.

128 Guilford, "'Creativity, ' Address" 80-83.

129 Torrance, Creativity in Classroom 12.

130 Crockenierg 35. 
131 Richard S. Mansfield, Thomas V. Busse and Ernest A. Krepelka, "The Effectiveness of Creativity Training," Review of Educational Research 48.4 (Fall 1978): 532.

132 Nathan Kogan and Ethel Pankove, "Long-Term Predictive Validity of Divergent-Thinking Tests: Some Negative Evidence," Journal of Educational Psychology 66.6 (1974): 803.

133 Torrance, "Education and Creativity" 89. See also: Eysenck $10-12$

\section{Crockenberg 31.}

135 Mansfield, Busse, Krepelka 519-531.

136 Donald J. Treffinger, John F. Feldhusen and Susan Bahlke Thomas, "Relationship Between Teachers' Divergent Thinking Abilities and Their Ratings of Pupils' Creative Thinking Abilities," Measurement and Evaluation in Guidance 3.3 (Fall 1970): 174-5.

137 Treffinger, Feldhusen and Thomas 175.

138 Guilford "Creativity: Quarter Century" 44-47.

139 Kogan and Pankove 308. See also: John G. Nicholls "Creativity in the Person Who Will Never Produce Anything Original and Useful," American Psychologist 27 (1972): 720-721.

140 Crockenberg 37.

141 Crockenberg 37-38.

142 Michael A. Wallach and Cliff W. Wing, Jr., The Talented

Student: A Validation of the Creativity-Intelligence Distinction (New York: Holt, Rinehart, 1969).

143 0.H. Feldman, "Faulty Construction: A Review of Wallach's and Wing's 'The Talented Student: A Validation of the 
Creativity-Intelligence Distinction, ' " Contemporary Psychology, 15.1 (1970): 3-4.

144 crockenberg 28.

145 Getzels and Jackson 199-260.

146 Morris I. Stein, Stimulating Creativity, 2 vols. (New York: Academic Press, 1974).

147 George S. Welsh, Creativity and Intelligence: A Personality Approach (Chapel Hi11, No. Carolina: Univ. of No. Carolina P, 1975).

148 Mednick 220-232.

149 George F. Kneller, The Art and Science of Creativity (New York; Holt, Rinehart, 1965).

150 welsh 55.

151 Steven Harvey, "A New View of the Relationship between Creativity and Intelligence," Journal for the Education of the Gifted 5.1 (1982): 295-306. See also: Eysenck 10-12. See al so: Guilford, Creativity: Quarter Century 50. See also: Thurstone 52-62.

152 Razik 303. See also: Guilford, Intelligence, Creativity 128-144.

153 Gowan and Demos 75. See also: Torrance, Creativity in Classroom 18. See also: Guilford, Intelligence, Creativity 84 .

154 Guilford, "Creativity: Quarter Century" 50.

155 Getzels and Jackson 120.

156 Gowan and Demos 79.

157 Brewster Ghiselin, The Creative Process Berkeley, Calif.: U.C. Berkeley P 1954).

158 Mednick 221. 
159 Mednick 221.

160 Mednick 221.

151 Mednick 224-5.

162 crockenberg 35.

163 Guilford, Intelligence, Creativity 14-57.

164 Guilford, Intelligence, Creativity 14-32.

165 Guilford, Intelligence, Creativity 40-42.

166 Guilford, Intelligence, Creativity 40.

167 Patrick, "Artists" 35-73. See also: C. Patrick, "Scientific Thought," Journal of Psychology 5 (1938): 55-83, and What Is Creative Thinking? (New York: Philosophical Lib., 1955).

168 Guilford, Intelligence, Creativity 202.

169 Derived from diagrams in Guilford, Intelligence, Creativity $40,220$.

170 Patrick, "Artists" 35-73.

171 Patrick, What Is?

172 Patrick, "Artists" 35-73.

173 Rosamond E.M. Harding, An Anatomy of Inspiration and An

Essay on the Creative Mind, 3rd ed. (Cambridge, Eng.: W. Heffer, 1948) 8-21. See also: Ghiselin. See also: A.E. Houseman, Selected Prose, ed. Joinn Carter (Cambridge, Eng.: Univ. P., 1961) 194-5. See al so: Charles Darwin, The Autobiography of Charles Darwin and Selected Letters, ed. Francis Darwin (New York: Dover, 1958) 43.

174 Ghiselin 12.

175 John Dewey, How We Think (Boston, Heath, 1910).

176 Torrance, "Developing" 32. 
177 Torrance, Creativity Classroom 6.

178 Torrance, "Developing" 39-41.

179 Torrance, Rewarding 8.

180 Torrance, Rewarding 8.

181 Guilford, Intelligence, Creativity 41.

182 Roe, "Artists" 401-408. See al so: Irving A. Taylor, "A Retrospective View of Creativity Investigation," Taylor and Getzels 16.

183 Roe ,"Scientists" 51.

184 Mary Henle, "The Birth and Death of Ideas," Contemporary Approaches to Creative Thinking: A Symposium Held at the University of Utah, eds. Howard E. Gruber, Glenn Terrell and Michael Wertheimer (New York: Atherton P, 1962) 43.

185 itenle 43.

186 May 39.

187 Roe, "Scientists" 49.

188 Pepinsky 83.

189 May 39-43.

190 E. Kris, Psychoanalytic Explorations in Art (New York: University $P, 1958)$.

191 Henle 46.

192 Norbert Weiner, Ex-Prodigy: My Childhood and Youth (Cambridge, Mass.: MIT P, 1953) 46.

193 Henle 45.

194 Patrick, What Is? 76.

195 Barron, "Disposition" 273. 
196 crutchfield 122.

197 May 42.

198 May 42. See also: Daniel P. Keating, "Four Faces of

Creativity: The Continuing Plight of the Intellectually Inderserved," Gifted Child Quarteriy 24.2 (Spring 1980): 56-62.

199 Gowan and Demos 83-87.

200 Jerome Bruner, "The Conditions of Creativity," Contemporary Approaches to Creative Thinking, eds. Howard E. Gruber et al. (New York: Atherton P, 1962) 4-16.

201 Patrick, What Is? 146-155

202 Torrance, "Education and Creativity" 92-102, See also: Torrance, "Developing" 42.

203 Leslie J. Chamberl in and Jerry Bergman, "The Mystery of Creativity Revealed," High School Journal 65-4 (Jan. 1982): 112. 204 Alex F. Osborn, "Developments in Creative Education," Parnes and Harding 20-22. See also: E. Paul Torrence and J. Pansy Torrance, Is Creativity Teachable? (Bloomington, Ind.: Phi Delta Kappa Educational Foundation, 1973): 8-10.

205 Harold Rugg, Imagination (New York: Harper \& Row, 1963) xv-xvi. See also: Cattell and Butcher 313, 324. See also: Getzels and Jackson 124. See also: Morris B. Parloff and Joseph H. Handlon, "The Influence of Criticialness on Creative Problem-Solving in Dyads," Psychiatry 27 (1964): 25-27. 206 Sidney J. Parnes, "Do You Really Understand Brainstorming?" Adult Leadership (April 1959); rpt. in Parnes and Harding 289. 207Cattell and Butcher 313. 
208 Cattell and Butcher 324.

209 Getzels and Jackson 124.

210 Getzels and Jackson 124.

211 Harold Rugg, Foundations for American Education (Younkers-on Hudson, New York: World Book, 1947) 447-8.

212 Patrick, What Is? 83, 147.

213 Patrick, What Is? 79.

214 Dewey, How Think 5.

215 Patrick, What Is? 4.

216 Bruner 11.

217 Patrick, What Is? 85.

218 Patrick, What Is? 87.

219 Torrance, Developing 35.

220 Patrick, What Is? 58.

221 poincare 27.

222 poincare 25.

223 Silvano Arieti, Creativity: The Magic Synthesis (New York:

Basic Books, 1976) 54 .

224 Arieti 54.

225 Arieti 54.

226 Arieti 55.

227 Arieti 61.

228 Arieti 61.

229 Arieti 61-2.

230 Arieti 62. See also: Torrance, "Developing" 40. See also: 
231 Arieti 62.

232 Arieti 62.

233 Gowan and Demos 53.

234 Gowan and Demos 53.

235 L.L. Thurstone, "Creative Talent," Applications of

Psychology, ed. L.L. Thrustone (New York: Harper \& Bros., 1952) 20; qtd. in Getzels and Jackson 8.

236 Getze 1 s and Jackson 25.

237 Torrance, "Education and Creativity" 89.

238 Torrance, Creativity in Classroom 11-12.

239 Torrance, "Education and Creativity" 100-102. See also:

Getzels and Jackson 30. See also: Kneller 8.

240 Wilson 33. See also: Patrick, What Is? 145-6. See also:

Rugg 447-8.

241 Calvin w. Taylor, "Tentative Descriptions of the Creative Individual;" rpt. in Parnes and Harding 175.

242 Don Fabun, Three Roads to Awareness (Beverley Hills, Cal if.: Glencoe, 1970) 4 .

243 Kant 526.

244 Kant 525.

245 Robert C. Wilson; qtd. in Parnes and Harding 33. See also: Patrick, What Is? 145. See also: Torrance, Rewarding 298.

246 American Heritage Dictionary, Second College Edition, (Boston: Houghton Mifflin, 1982) 553. 


\section{BIBLIOGRAPHY}

Anderson, Harold H., ed. Creativity and Its Cultivation. New York: Harper \& Bros., 1959.

Andres, Elizabeth. "The Development of Imagination in the Pre-School Child." U. of Iowa Studies in Character 3.4 (1930).

Andrews, Frank. "Sociological and Psychological Factors Which Influence the Creative Process." Taylor and Getzels 1-30.

Andrews, Michael F. Creativity and Psychological Health. New York: Syracuse U., 1961.

Arieti, Silvano. Creativity: The Magic Synthesis. New York: Basic Books, 1976.

Aschner, Mary Jane and Charles E. Bish, eds. Productive Thinking in Education. Washington, D.C.: National Education Assn., 1963.

Bacon, Sir Francis. Novum Organum. Chicago: U. of Chicago P, 1952.

Barron, Frank. Creative Person and Creative Process. New York: Hoit, 1969.

- Creativity and Personal Freedom. New York: Van Nostrand, 1968. "The Disposition towards Originality." Journal of Abnormal and Social Psychology 51 (1966): 478-85.

- Research Monograph \#3: An Eye More Fantastical. Washington, D.C.: National Art Education Assn., 1962.

Bl anchard, Brand. The Nature of Thought. 2 vols. New York: Humanities $P, 1939$.

Brown, G. I. Human Teaching of Human Learning. New York: Viking, 1971.

Brown, George I., Mark Phillips and Stanley Shapiro. Getting It All Together: Confluent Education. Bloomington, Ill.: Phi Delta Kappa Educational Foudnation, 1976. 
Bruner, Jerome S. "The Conditions of Creativity." Contemporary Approaches to Creative Thinking. Ed. Howard W. Gruber, GTenn Terrell and Michael Wertheimer. New York; Atherton P, 1962. 1-30.

Busse, Thomas V., and Richard S. Mansfield. "Theories of the Creative Process: A Review and Perspective." Journal of Creative Behavior 14.2 (1980): 91-103, 132.

Carro11, Herbert A. Genius in the Making. New York: McGraw, 1940.

Cassirer, Ernst. The Philosophy of the Enlightenment. Princeton, N.J.: Princeton UP, 1951.

Cattell, R. B. and H. J. Butcher. "Creativity and Personality." Excerpt from Cattell and Butcher, The Prediction of Achievement and Creativity. New York: Bobbs, 1968. Rpt. in Vernon 312-26.

Chamberlin, Les]ie J. and Jerry Bergman. "The Mystery of Creativity Revealed." High School Journal 65-4 (Jan. 1982): 112-117.

Chassell, L. M. "Tests for Originality." Journal of Educational Psychology 7 (1916): 317-328.

Cooper, Anthony Ashley, Third Earl of Shaftsbury. Characteristics of Men, Manners, Opinions, Times. Ed. John M. Robertson. New York: Bobbs, 1964.

Cox, Catherine. Genetic Studies of Genius, Vol. II: The Early Mental Traits of Three Hundred Geniuses. Stanford, Calif: Stanford UP, 1926.

Crockenberg, Susan B. "Creativity Tests: A Boon or Boondoggle for Education?" Review of Educational Research 42.1 (1972): 27-45.

Cronbach, Lee J. "Intelligence? Creativity? A Persimonious Reinterpretation of the Wallach-Kogan Data." American Educational Research Journal Nov. 1968: 491-511.

Crutchfield, Richard S. "Conformity and Creative Thinking." Gruber et al. 120-140.

Darwin, Charles. The Autobiography of Charles Darwin and Selected Letters. Ed. Francis Darwin. New York: Dover: 1958.

Dauw, Dean C. and Al an J. Fredian, eds. Creativity and Innovation in Organizations. Dubuque, Iowa: Hunt Pub., 1971.

Dewey, John. Art as Experience. New York: Capricorn, 1958. (Originally pub. 1934).

- Experience and Nature. New York: Dover, 1958. (Originally pub. 1929. 
- How We Think. Boston: Heath, 1910.

Dearborn, G. V. A Study of Imagination." American Journal of Psychology 5.9 (1898) 183-190.

Dodds, E. R. The Greeks and the Irrational. Boston: Beacon, 1957.

Downey, J. E. Creative Imagination. New York: Harcourt, 1929.

Ellison, R. L. and C. W. Taylor. Alpha Biographical Inventory. Salt Lake City, Utah: Institute for Behavioral Research in Creativity, 1968.

Eysenck, Hans J. "The Roots of Creativity: Cognitive Ability or Personality Traits?" Roeper Review May 1983: 10-12.

Fabun, Don. Three Roads to Awareness. Beverley Hills, Calif.: Glencoe P. 1970 .

Feldman, D. H. "Faulty Construction: A Review of Wallach's and Wing's 'The Talented Student: A Validation of the

Creativity-Intelligence Distinction.'" Contemporary Psychology 15.1 (1970).

Ferguson, W. K., ed. Facets of the Renaissance. New York: Harper, 1959.

Ferguson, W. K., Robert Lopez, et al. The Renaissance: Six Essays. New York: Academy Lib., 1953.

Franklin, Adele. "The Teacher's Role in Creativity Symposium, 1958: I. The Problem of Spontaneity, Initiative and Creativity in Suburban Classrooms." American Journal of Orthopsychiatry 29 (1954): 266-79.

Galton, Sir Franics. Hereditary Genius: An Inquiry into Its Laws and Consequences. New York: Horizon P, 1952.

Getzels, Jacob W. and M. Csikskentmihalyi. "From Problem Solving to Problem Finding." Taylor and Getzels 90-112.

Getzels, Jacob W. and Philip W. Jackson. Creativity and Intelligence. New York: Wiley, 1962.

Ghiselin, Brewster. The Creativity Process: A Symposium. Berkeley, Calif.: UC Berkeley P, 1954.

Gilbert, Katherine Everett and Helmut Kuhn. A History of Aethetics: Revised and Enlarged. New York: Dover, 1972.

Gowan, John Curtis and George D. Demos. The Education and Guidance of the Ablest. Springfield, I11.: Chas. C. Thomas, 1964. 
Gowan, John Curtis, George D. Demos and E. Paul Torrence, eds. Creativity: Its Educational Implications. New York: Wiley, 1967.

Gruber, Harold E., Glenn Terre11, and Michael Wertheimer, eds. Contemporary Approaches to Creative Thinking. New York: Atherton P, 1962.

Guilford, J. P. "'Creativity,' Address of the President of the American Psychological Association, Penn, State College, September, 1950." The American Psychologist 5 (1950): 444-454. Rpt. in Guilford, Intelligence 18-96.

"Creativity: A Quarter Century of Progress." Taylor and Getzels 37-59.

"Creativity: Yesterday, Today, and Tomorrow." Journal of Creative Behavior 1 (1979): 3-13. Rpt. in Guilford, Intelligence 6-18.

"Factors that Aid and Hinder Creativity." Teacher College Record 5 (1962): 63. Rpt. in Dauw and Fredian 75-94.

- Intelligence, Creativity and Their Educational Implications. San Diego: Knapp, 1968.

- "Three Faces of Intellect." American Psychologist 14 (1959): 469-79. Rpt. in D. Wolfe 107-132.

- "Traits of Creativity." Anderson 142-61.

Harding, Rosamond E. M. Antomy of Inspiration: An Essay on the Creative Mood. 3rd Ed. Cambridge, Eng.: W. Heffer, 1948.

Hartmann, G. "Insight vs Trial and Error in the Solution of Problems." American Journal of Psychology 45 (1933): 663-77.

Harvey, 0. J., James K. Hoffmeister, Carolie Coates and B. Jack White. "A Partial Evaluation of Torrence's Tests of Creativity." American Educational Research Journal May 1970: 359-72.

Harvey, Steven. "A New View of the Relationship Between Creativity and Intelligence." Journal for the Education of the Gifted 5.4 (1982): 295-306.

Henle, Mary. "The Birth and Death of Ideas." Gruber et al. 31-62. Henry, Jules. "The Teacher's Role in Creativity." American Journal of Orthopsychiatry 27 (1954): 266-79. 
Homer. The Iliad of Homer. Trans. Richard Lattimore. Chicago: $U$ of Chicago P, 1951.

- The Iliad of Homer and The Odyssey. Trans. Samuel Butler. Chicago: William Benton Pub., 1971.

Housman, A.E. Selected Prose. Ed. John Carter. Cambridge, Eng.: University P, 1961.

Houtz, John C. and Stuart M. Speedie. "Processes Underlying Divergent Thinking and Problem Solving." Journal of Educational

Psychology 70.5 (1978): 848-54.

Jacobson, Arthur C. Genius: Some Revaluations. Port Washington, New York: Kennikat P, 1926.

Jastrow, J. The Subconscious. New York: Houghton, 1906.

Kant, Immanuel. The Critique of Pure Reason, The Critique of Practical Reason, The Critique of Judgement. Trans. J. $C$. Meredith. Chicago: William Benton Pub., 1971.

Keating, Daniel P. "Four Faces of Creativity: The Continuing Plight of the Educationally Underserved." Gifted Child Quarterly 24.2 (1980): 56-62.

Kenmore, Dallas. The Nature of Genius. London: Peter Owen Ltd., 1960.

Kneller, George F. The Art and Science of Creativity. New York: Holt, 1965.

Kogan, Nathan, and Ethel Pankove. "Long-Term Predictive Validity of Divergent-Thinking Tests: Some Negative Evidence." Journal of Educational Psychology 66.6 (1974): 802-810.

Kris, E. Psychoanalytic Explorations in Art. New York; University P. 1958.

Kristeller, Paul Oskar. "Renaissance Platonism." Ferguson, Facets 103-123.

Lowes, J. L. The Road to Xanadu. New York: Houghton, 1930.

Mackinnon, Donald W. "IPAR's Contribution to the Conceptualization and Study of Creativity." Taylor and Getzels 60-89.

"The Nature and Nurture of Creative Talent." American Psychologist 17.7 (1962): 484-95. Rpt. in Dauw and Fredian 95-124. 
"The Personality Correlates of Creativity: A Study of American Architects." Proc. of the Fourteenth Congress on Applied Psychology. VoT. 2. Munsgaard, 1962: 11-39. Rpt. in Vernon 289-311.

Malgady, Robert G., and Peter R. Barcher. "Psychological Scaling of Essay Creativity: Effects of Productivity and Novelty." Journal of Educational Psychology 69.5 (1977): 512-518.

Malzman, Irving, Seymour Simon, David Raskin, and Leonard Licht. "Effects of Different Amounts of Training on Originality." Univ. of California, Dept. of Psychology, Aug. 1959, Technical Reports 3 and 4 under contracts Nonr 233(50) for the Office of Naval Research. Synopsized in Parnes and Harding 354-61.

Mansfield, Richard A., Thomas V. Busse and Ernest J. Krepelka. "The Effectiveness of Creative Training." Review of Educational Research 48.4 (Fall 1978): 517-536.

Maslow, A. H. "Emotional Blocks to Creativity." Paper delivered at Creative Engineering Seminar, U.S. Army Engineering School, Fort Belvoir, Virginia, April 1957. Rpt. in Parnes and Harding 93-103.

May, Rolo. The Courage to Create. New York: Bantam: 1975.

McLean, George F., and Patrick J. Aspell. Readings in Ancient Western Philosophy. New York: Appleton, 1970.

Mednick, S. A. "The Associative Basis of the Creative Process." Psychology Review 69-3 (1962): 220-232.

Mednick, S. A. and M. T. Mednick. Remote Associations Test. Boston: Houghton, 1967.

Mirandola, Pico della. Oration on the Dignity of Man. Trans. A. R. Caponigri. Chicago: Henry Regnery, 1956.

Mitzel, Harold E. "Creativity." Encyclopedia of Educational Research. Ed. Harold E. Mitzel. Vol. 1. 5th Ed. New York: Free Press, 1982. 385-393.

Mooney, R. L. "A Conceptual Model for Integrating Four Approaches to the Identification of Creative Talent." Scientific Creativity: Its Recognition and Development. Ed. C.W. Taylor and Frank Barron. New York: Wiley, 1963. 331-340.

Mooney, Ross L., and Taher A. Razik. Explorations in Creativity. New York: Harper, 1967.

Mouly, G.J. Psychology of Effective Thinking. 3rd ed. New York: Holt, 1973. 
Murray, Henry A. "Vicissitudes of Creativity." Anderson 96-118.

Myers, R. E., and E. Paul Torrance. "Can Teachers Encourage Creative Thinking?" Educational Leadership 1961: 156-159.

Nicholls, John G. "Creativity in the Person Who Will Never Produce Anything Original or Useful: The Concept of Creativity as a Normally Distributed Trait." American Psychologist 27 (1972) 712-725.

Osborn, Alex F. "Developments in Creative Education." Address to the 6th Annual Creative Problem-Solving Institute at the Univ. of Buffalo, 1960. Rpt. in Parnes and Harding 19-30.

Panofsky, Erwin. "The Renaissance: Artist, Scientists, Genius: Notes on the Renaissance Dammerung." Ferguson, Renaissance 121-182.

Parloff, Morris B., and Joseph H. Handlon. "The Influence of Criticalness on Creative Problem-Solving in Dyads." Psychiatry 27 (1964): 17-27.

Parnes, Sidney J. Creative Behavior Guidebook. New York: Scribner's, 1967.

- "Do You Really Understand Brainstorming?" Adult Leadership April 1959. Parnes and Harding 283-290.

Parnes, Sidney J. and H. F. Harding, eds. A Source Book for Creative Thinking. New York: Scribner's, 1982.

Patrick, C. "Creative Thought in Artists." Journal of Psychology 4 (1937) 35-73.

- "Scientific Thought." Journal of Psychology 5 (1938) 55-83.

- What Is Creative Thinking? New York: Philosophical Lib., 1955.

Pepinsky, Pauline N. "A Study of Productive Nonconformity." Gifted Child Quarterly Winter 1960: 81-86.

Plato. The Dialogues of Plato. Trans. B. Jowett. 2 vols. New York: Random, 1937.

Poincare, Henri. "Mathematical Creation." The Foundations of Science. Trans. George B. Halstead. Lancaster, Penn.: Science P, 1915. Rpt. in Ghisel in 22-31.

Razik, Taher A. "Psychometric Measurements of Creativity." Ross L. Mooney and Taher A. Razik, eds. Explorations in Creativity. New york: Harper, 1967. 301-309. 
Roe, Anne. "A Psychologist Examines Sixty-Four Eminent Scientists." Scientific American 187 (1952): 21-5. Rpt. in Vernon 43-51. "Painters and Painting." Taylor and Getzels 157-172. "The Personality of Artists." Educ. Psychol. Measmt. 6 (1946): 401-08.

Rogers, C. R. "Toward a Theory of Creativity." ETC: A Review of General Semantics 11.4 (1954): 249-60. Rpt. in Anderson 69-82.

Rosner, Stanley and Lawrence E. Abt, eds. Essays in Creativity. Cronton-on-Hudson, New York: North River P, 1974.

Rossman, J. The Psychology of the Inventor. Washington, D.C.: Inventors Pub., 1931 .

Rothenberg, Albert and Carl R. Hausman. The Creativity Question. Durham, N.C.: Duke UP, 1976.

Rugg, Harold. Foundations for American Education. Yonkers-on-Hudson, New York: World Book, 1947.

- Imagination. New York: Harper, 1963.

Simonton, Dean Keith. Genius, Creativity, and Leadership. Cambridge, Mass.: Harvard UP, 1984.

Sinnott, E. W. "The Creativeness of Life." H.H. Anderson, ed. Creativity and Its Cultivation. New York: Harper, 1959. 21-9. Rpt. in Vernon 107-115.

Smith, Paul, ed. Creativity. New York: Hastings, 1959.

Sne11, Bruno. The Discovery of the Mind. New York: Harper and Bros., 1960.

Stein, Morris I. Stimulating Creativity. 2 vols. New York: Academic P, 1974.

Storr, Anthony. The Dynamics of Creation. New York: Atherton, 1972.

Summerfield, Jack $D$. and Loriyn Thatcher. The Creative Mind and Method. New York: Russel1 and RusseTT, 1964.

Taylor, Calvin W. Creativity: Progress and Potential. New York: McGraw, 1964.

, ed. The Second (1957) University of Utah Convention on the Identification of Creative Scientific Talent. Salt Lake City, Utah: U of Utah P, 1958. 
"Tentative Description of the Creative Individual." A paper at the 2nd Minnesota Conference on Gifted Children at the University of Minnesota, October, 1964. Rpt. in Parnes and Harding 169-182.

Taylor, Calvin W. and Frank Barron. Scientific Creativity: Its Recognition and Development. New York: Wiley, 1963.

Taylor, Calvin W. and Robert L. Ellison. "Moving Toward Working Models in Creativity: Utah Creativity Experiences and Insights." Taylor and Getzels 192-223.

Taylor, Irving A. "An Emerging View of Creative Actions." Taylor and Getzels 297-325.

"A Retrospective View of Creativity Investigation." Taylor and Getzels 1-36.

- Widening Horizons in Creativity. New York: Wiley, 1964.

Taylor, Irving A. and Jacob W. Getzels, eds. Perspectives in Creativity. Chicago: Aldine Pub., 1975.

Terman, Lewis M. The Gifted Group at Mid-Life: Vol. V of Genetic Studies of Genius. Stanford, Calif.: Stanford UP, 1948. "Psychological Approaches to the Biography of Genius." Vernon 25-42.

Terman, Lewis M. and Melita H. Ogden. The Gifted Child Grows Up: Vol. IV of Genetic Studies of Genius. Stanford, Calif.: Stanford UP, 1947.

Thacker, Bernard T. and Edward S. Rosenbluh. "Creativity as a Reflection of Teacher-Pupil Relationships." Psychology 9.1 (1972): 23-26.

Thurstone, L. L. "The Scientific Study of Inventive Talent." Paper delivered at the Industrial Research Institute Conference on the Nature of Creative Thinking, May 6, 1952. Rpt. in Parnes and Harding 52-62.

Torrance, E. Paul. "Can We Teach Children to Think Creatively?" Journal of Creative Behavior. 50 (1972): 176-182.

- Creativity in the Classroom. Washington, D.C.: National Education Assn., 1977.

- "Creativity Research in Education: Still Alive." Getzels and Jackson 278-96. 
"Developing Creative Thinking Through School Experiences." Paper given at Minneapolis Teachers League, May, 1959. Rpt. in Parnes and Harding 31-47.

- "Education and Creativity." C. W. Taylor, Creativity 49-128.

- Education and the Creative Potential. Minneapolis, Minn.: U of Minn. P. 1963.

- Encouraging Creativity in the Classroom. Dubuque, Iowa: Wm. C. Brown, 1970 .

"Factors Affecting Creative Thinking in Children: An Iterim Report." Merrill-Palmer Quarterly 1961: 171-80.

- Guiding Creative Talent. Englewood Cliffs, N.J.: Prentice, 1962.

- Guiding the Gifted and Talented. Englewood Cliffs, N.J.: Prentice, 1962.

- Is Creativity Teachable? Bloomington, Ind.: Phi Delta Kappa Educ. Foundation, 1973.

- Rewarding Creative Behavior. Englewood Cliffs, N.J.: Prentice, 1965.

- Torrence Tests of Creative Thinking: Norms Technical Manual. Englewood CTiffs, N.J.: Prentice, 1965.

Torrance, E. Paul. and R. K. Gupta. Development and Evaluation of Recorded Programmed Experiences in Creative Thinking in the Fourth Grade. Minneapolis, Minn.: Bureau of Educational Research, U. of Minn., 1964.

Torrance, E. Paul and R. E. Myers. Creative Learning and Teaching. New York: Dodd, Mead, 1970.

Torrance, E. Paul and J. Pansy Torrance. Is Creativity Teachable? Bloomington, Ind.: Phi Delta Kappan Educ. Foundation, 1973.

Torrance, E. Paul, Conchita A. Tan and Thomas Allman. "Verbal Originality and Teacher Behavior: A Predictive Validity Study." Journal of Teacher Education 21.3 (1970): 335-41.

Toynbee, Arnold. "Has America Neglected Her Creative Minority?" Utah Al umnus (February 1962) 10. Rpt. in C. W. Taylor, Second 3-9.

Treffinger, Donald J. "Gifted Students, Regular Classrooms, Sixty Ingredients for a Better Blend." The El ementary School Journal 82.3 (1982): 267-73. 
Treffinger, Donald J., John F. Feldhusen and Susan Bahlke Thomas. "Relationship Between Teachers' Divergent Thinking Abilities and Their Pupils' Creative Thinking Abilities." Measurement and Evaluation in Guidance 3.3 (Fall 1970): 169-76.

Trinkhaus, Charles. In Our Image and Likeness. 2 vols. London: Constable, 1970 .

Tumin, Melvin. "Obstacles to Creativity." ETC: A Review of General Semantics 15 (1954): 105-113. Rpt. in Parnes and Harding 105-113.

Vasari, Giorgio. Lives of the Artists. Trans. George Bull. Middlesex, Eng.: Penguin, 1965.

Vernon, P. E., ed. Creativity. Middlesex, Eng.: Penguin, 1970.

Wall ach, Michael A., and N. Kogan. Modes of Thinking in Young

Children. New York: Holt, 1965.

Wallach, Michael A., and Cliff W. Wing, Jr. The Talented Student: A Validation of the Creativity-Intelligence Distinction. New York: Hoit, 1969.

Wallas, G. The Art of Thinking. New York: Harcourt, 1926.

Wasserman, Earl R., ed. Aspects of the Eighteenth Century.

Bal timore, Md.: Johns Hopkins UP, 1965.

Weiner, Norbert. Ex-Prodigy: My Childhood and Youth. Cambridge, Mass.: MIT P, 1953.

Welsh, George S. Creativity and Intelligence: A Personality Approach. Chapel Hill, NC: U. of NC, 1975.

Wertheimer, Max. Productive Thinking. New York: Harper \& Bros., 1945.

Wilson, Robert C. "Developing Creativity in Children." Education Sept. 1960: 19-23.

Wolfe, Dael, ed. The Discovery of Thought. Cambridge, Mass.: Harvard UP, 1969.

Wolfe, Thomas. The Story of a Novel. New York: Scribner's, 1936. Rpt. in Ghiselin I92-205.

Woods, Frederick Adams. ns 33.850 (1911): 568-574. 
Woodworth, R.S. Experimetal Psychology. New York: Holt: 1938.

- Psychology; A Study of Mental Life. New York: Holt, 1921.

Yamamoto, Kaoro. "Relationships Between Creative Abilities of Teachers and Achievement and Adjustment of Pupils." The Journal of Experimental Education (Fall 1963): 3-24.

Zilboorg, Gregory. "The Psychology of the Creative Personality." Smith 21-32. 